\title{
Cholinesterase inhibitors for Parkinson's disease dementia (Review)
}

\author{
Maidment I, Fox C, Boustani M
}

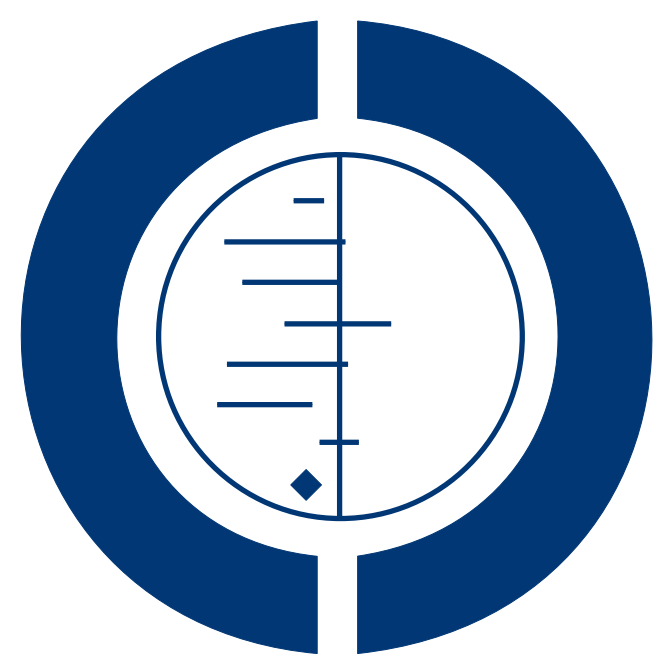

\section{THE COCHRANE COLLABORATION $^{\circledR}$}

This is a reprint of a Cochrane review, prepared and maintained by The Cochrane Collaboration and published in The Cochrane Library 2006, Issue 1

http://www.thecochranelibrary.com

\section{WILEY}


TABLE OF CONTENTS

HEADER . . . . . . . . . . . . . . . . . . . . . . . . . . . . . . . . . . . . . . . . . . . . . . . . . . . . . .

ABSTRACT . . . . . . . . . . . . . . . . . . . . . . . . . . . . . . . . . . . . . . . . . . . . . . . . . .

PLAIN LANGUAGE SUMMARY . . . . . . . . . . . . . . . . . . . . . . . . . . . . . . . . . . . . . . . . . . .

BACKGROUND . . . . . . . . . . . . . . . . . . . . . . . . . . . . . . . . . . . . . 2

OBJECTIVES . . . . . . . . . . . . . . . . . . . . . . . . . . . . . . . . . . . . . . . . . . . . . . . . . . .

METHODS . . . . . . . . . . . . . . . . . . . . . . . . . . . . . . . . . . . . . . . 3

RESULTS . . . . . . . . . . . . . . . . . . . . . . . . . . . . . . . . . . . . . . . . . . .

DISCUSSION . . . . . . . . . . . . . . . . . . . . . . . . . . . . . . . . . . . . . . . . . . . .

AUTHORS' CONCLUSIONS . . . . . . . . . . . . . . . . . . . . . . . . . . . . . . . . . . . . . . . . . .

ACKNOWLEDGEMENTS . . . . . . . . . . . . . . . . . . . . . . . . . . . . . . . . . . . . . . . . . . . . . .

REFERENCES . . . . . . . . . . . . . . . . . . . . . . . . . . . . . . . . . . . . . . 7

CHARACTERISTICS OF STUDIES . . . . . . . . . . . . . . . . . . . . . . . . . . . . . . . . . . . . . . . . . . .

DATA AND ANALYSES . . . . . . . . . . . . . . . . . . . . . . . . . . . . . . . . . . . . . . . . . .

Analysis 1.1. Comparison 1 Rivastigmine (3-12mg/day) vs placebo, Outcome 1 ADAS-Cog (change from baseline at 24

weeks) LOCF. . . . . . . . . . . . . . . . . . . . . . . . . . . . . . . . . . .

Analysis 1.2. Comparison 1 Rivastigmine (3-12mg/day) vs placebo, Outcome 2 ADCS-CGIC (change from baseline at 24 weeks) LOCF. . . . . . . . . . . . . . . . . . . . . . . . . . . . . . . . . . . 16

Analysis 1.3. Comparison 1 Rivastigmine (3-12mg/day) vs placebo, Outcome 3 ADCS-ADL (change from baseline at 24 weeks) LOCF. . . . . . . . . . . . . . . . . . . . . . . . . . . . . . . . . . . . . . . . . 16

Analysis 1.4. Comparison 1 Rivastigmine (3-12mg/day) vs placebo, Outcome 4 NPI-10 (change from baseline at 24 weeks) LOCF.

Analysis 1.5. Comparison 1 Rivastigmine (3-12mg/day) vs placebo, Outcome 5 MMSE (change from baseline at 24 weeks) LOCF.

Analysis 1.6. Comparison 1 Rivastigmine (3-12mg/day) vs placebo, Outcome 6 CDR (change from baseline at 24 weeks) LOCF.

Analysis 1.7. Comparison 1 Rivastigmine (3-12mg/day) vs placebo, Outcome 7 D-KEFS (change from baseline at 24 weeks) LOCF.

Analysis 1.8. Comparison 1 Rivastigmine (3-12mg/day) vs placebo, Outcome 8 Withdrawals before end of treatment at 24 weeks.

Analysis 1.9. Comparison 1 Rivastigmine (3-12mg/day) vs placebo, Outcome 9 Withdrawals due to adverse event before end of treatment at 24 weeks.

Analysis 1.10. Comparison 1 Rivastigmine (3-12mg/day) vs placebo, Outcome 10 Number of deaths before end of treatment at 24 weeks. . . . . . . . . . . . . . . . . . . . . . . . . . . . . . . .

Analysis 1.11. Comparison 1 Rivastigmine (3-12mg/day) vs placebo, Outcome 11 At least one adverse event before end of treatment at 24 weeks. . . . . . . . . . . . . . . . . . . . . . . . . . . . . . . . . . . . . . .

Analysis 1.12. Comparison 1 Rivastigmine (3-12mg/day) vs placebo, Outcome 12 At least one adverse event of nausea before end of treatment at 24 weeks.

Analysis 1.13. Comparison 1 Rivastigmine (3-12mg/day) vs placebo, Outcome 13 At least one adverse event of vomiting before end of treatment at 24 weeks.

Analysis 1.14. Comparison 1 Rivastigmine (3-12mg/day) vs placebo, Outcome 14 At least one adverse event of tremor before end of treatment at 24 weeks.

Analysis 1.15. Comparison 1 Rivastigmine (3-12mg/day) vs placebo, Outcome 15 At least one adverse event of diarrhoea before end of treatment at 24 weeks.

Analysis 1.16. Comparison 1 Rivastigmine (3-12mg/day) vs placebo, Outcome 16 At least one adverse event of anorexia before end of treatment at 24 weeks.

Analysis 1.17. Comparison 1 Rivastigmine (3-12mg/day) vs placebo, Outcome 17 At least one adverse event of a fall before end of treatment at 24 weeks.

Analysis 1.18. Comparison 1 Rivastigmine (3-12mg/day) vs placebo, Outcome 18 At least one adverse event of dizziness before end of treatment at 24 weeks. . . . . . . . . . . . . . . . . . . . . . . . . . . . . . . . . . . .

Analysis 1.19. Comparison 1 Rivastigmine (3-12mg/day) vs placebo, Outcome 19 At least one adverse event of hypotension before end of treatment at 24 weeks.

Cholinesterase inhibitors for Parkinson's disease dementia (Review)

Copyright $\odot 2010$ The Cochrane Collaboration. Published by John Wiley \& Sons, Ltd. 
Analysis 1.20. Comparison 1 Rivastigmine (3-12mg/day) vs placebo, Outcome 20 At least one adverse event of constipation before end of treatment at 24 weeks.

Analysis 1.21. Comparison 1 Rivastigmine (3-12mg/day) vs placebo, Outcome 21 At least one adverse event of hallucinations before end of treatment at 24 weeks. . . . . . . . . . . . . . . . . . . . . . . . .

Analysis 1.22. Comparison 1 Rivastigmine (3-12mg/day) vs placebo, Outcome 22 At least one adverse event of confusion before end of treatment at 24 weeks. . . . . . . . . . . . . . . . . . . . . . . . . . . . . . . . . . . . . . . . . 26

Analysis 1.23. Comparison 1 Rivastigmine (3-12mg/day) vs placebo, Outcome 23 At least one adverse event of orthostatic hypotension before end of treatment at 24 weeks. . . . . . . . . . . . . . . . . . . . . . . . . . . . . . 26

WHAT'S NEW . . . . . . . . . . . . . . . . . . . . . . . . . . . . . . . . . . . . . . 26

HISTORY . . . . . . . . . . . . . . . . . . . . . . . . . . . . . . . . . . . . . . . . . .

CONTRIBUTIONS OF AUTHORS . . . . . . . . . . . . . . . . . . . . . . . . . . . . . . . . . . . . . . . . . . . . .

DECLARATIONS OF INTEREST . . . . . . . . . . . . . . . . . . . . . . . . . . . . . . . . . . . 27

SOURCES OF SUPPORT . . . . . . . . . . . . . . . . . . . . . . . . . . . . . . . . . . . 27

INDEX TERMS . . . . . . . . . . . . . . . . . . . . . . . . . . . . . . . . . . . . . . 28 


\title{
[Intervention Review]
}

\section{Cholinesterase inhibitors for Parkinson's disease dementia}

\author{
Ian Maidment ${ }^{1}$, Chris Fox ${ }^{2}$, Malaz Boustani ${ }^{3}$ \\ ${ }^{1}$ University of Kent, East Kent NHS and Social Care Partnership Trust, Canterbury, UK. ${ }^{2}$ Kent Institute of Medical Sciences, University \\ of Kent Department of Mental Health, Folkestone, UK. ${ }^{3}$ Regenstrief Institute, Inc., Indianapolis, Indiana 46202-2872, USA \\ Contact address: Ian Maidment, University of Kent, East Kent NHS and Social Care Partnership Trust, Trust HQ, Littlebourne Road, \\ Canterbury, Kent, UK. ian.maidment@nhs.net.
}

Editorial group: Cochrane Dementia and Cognitive Improvement Group.

Publication status and date: Stable (no update expected for reasons given in 'What's new'), published in Issue 1, 2010.

Review content assessed as up-to-date: 5 May 2008.

Citation: Maidment I, Fox C, Boustani M. Cholinesterase inhibitors for Parkinson's disease dementia. Cochrane Database of Systematic Reviews 2006, Issue 1. Art. No.: CD004747. DOI: 10.1002/14651858.CD004747.pub2.

Copyright (C) 2010 The Cochrane Collaboration. Published by John Wiley \& Sons, Ltd.

\begin{abstract}
A B S T R A C T
Background

The loss of cholinergic, dopaminergic and noradrenergic innervations seen in Parkinson's Disease Dementia (PDD) suggest a potential role for cholinesterase inhibitors. Concerns have been expressed about a theoretical worsening of Parkinson's disease related symptoms, particularly movement symptoms.
\end{abstract}

\section{Objectives}

To assess the efficacy, safety, tolerability and health economic data relating to the use of cholinesterase inhibitors in PDD.

\section{Search methods}

The trials were identified from the Specialized Register of the Cochrane Dementia and Cognitive Improvement Group on 19 April 2005 using the search term parkinson*. This register contains records from major health care databases and many ongoing trial databases and is updated regularly.

Comprehensive searches of abstracts from major scientific meetings were performed. Pharmaceutical companies were approached for information regarding additional and ongoing studies.

\section{Selection criteria}

Randomized, double-blind, placebo-controlled studies assessing the effectiveness of cholinesterase inhibitors in PDD. Inclusion and exclusion criteria were stated to limit bias.

\section{Data collection and analysis}

Two reviewers (IM, CF) independently reviewed the quality of the studies utilizing criteria from the Cochrane Collaboration Handbook. Medications were examined separately and as a group. The outcome measures assessed were in the following domains: neuropsychiatric features, cognition, global impression, daily living activities, quality of life, burden on caregiver, Parkinsonian related symptoms, treatment acceptability as determined by withdrawal from trials, safety as determined by the frequency of adverse events, institutionalisation, death and health economic factors.

Cholinesterase inhibitors for Parkinson's disease dementia (Review)

Copyright $\odot 2010$ The Cochrane Collaboration. Published by John Wiley \& Sons, Ltd. 


\section{Main results}

A detailed and systematic search of relevant databases identified one published randomized, double-blind, placebo-controlled study (Emre 2004) involving 541 patients that compared rivastigmine with placebo. Rivastigmine produced statistically significant improvements in several outcome measures. On the primary cognitive measure, the ADAS-Cog, rivastigmine was associated with a 2.80 point ADAS-Cog improvement [WMD -2.80, 95\% Cl -4.26 to -1.34, P = 0.0002] and a 2.50 point ADCS-ADL improvement [95\% Cl 0.43 to $4.57, \mathrm{P}=0.02$ ] relative to placebo. Clinically meaningful (moderate or marked) improvement occurred in $5.3 \%$ more patients on rivastigmine, and meaningful worsening occurred in $10.1 \%$ more patients on placebo.

Tolerability appeared to be a significant issue. Significantly more patients on rivastigmine dropped out of the study due to adverse events [62/362 versus $14 / 179$, OR $2.44,95 \% \mathrm{Cl} 1.32$ to $4.48, \mathrm{P}=0.004]$. Nausea [20/179 versus $105 / 362, \mathrm{OR} 3.25,95 \% \mathrm{Cl} 1.94$ to $5.45, \mathrm{P}<0.00001]$, tremor [7/179 versus $37 / 362$, $\mathrm{OR} 2.80,95 \% \mathrm{Cl} 1.22$ to $6.41, \mathrm{P}=0.01$ ] and in particular vomiting [3/179 versus 60/362, OR $11.66,95 \% \mathrm{Cl} 3.60$ to $37.72, \mathrm{P}<0.0001$ ] were significantly more common with rivastigmine. However, significantly fewer patients died on rivastigmine than placebo [ $4 / 362$ versus $7 / 179$, OR $0.27,95 \%$ CI 0.08 to $0.95, \mathrm{P}=0.04$ ]

\section{Authors' conclusions}

Rivastigmine appears to improve cognition and activities of daily living in patients with PDD. This results in clinically meaningful benefit in about $15 \%$ of cases. There is a need for more studies utilising pragmatic measures such as time to residential care facility and both patient and carer quality of life assessments. Future trials should involve other cholinesterase inhibitors, utilise tools to analyse the data that limit any bias and measure health economic factors. It is unlikely that relying solely on the last observation carried forward (LOCF) is sufficient. Publication of the observed case data in the largest trial would assist (Emre 2004). Adverse events were associated with the cholinergic activity of rivastigmine, but may limit patient acceptability as evidenced by the high drop out rate in the active arm.

\section{PLAIN LANGUAGESUMMARY}

\section{Rivastigmine appears to moderately improve cognition and to a lesser extent activities of daily living in patients with PDD}

Dementia is frequently associated with Parkinson's Disease. While a number of neurotransmitters appear to be involved, loss of cholinergic functioning is particularly associated with Parkinson's Disease Dementia (PDD) suggesting a potential utility for cholinesterase inhibitors. Rivastigmine appears to moderately improve cognition and to a lesser extent activities of daily living in patients with PDD. There was a clinically meaningful benefit in $15 \%$ of patients. Efficacy in other domains requires confirmation. Tolerability in particular nausea, vomiting and tremor appear problematic.

\section{B A C K G R O U N D}

The prevalence of dementia in Parkinson's disease (PD) is six times higher than in the general population (Aarsland 2001). The prevalence of dementia in people with Parkinson's disease varies widely from $4 \%$ to $93 \%$, based on study design, dementia definition and population selection, with an overall prevalence of $40 \%$ (Cummings 1988; Emre 2003; Erkinjuntti 1997; Zhang 1993). The condition usually develops in people over the age of 65 , and old age has been identified as a risk factor for Parkinson's Disease Dementia (PDD) (Aarsland 2001; Aarsland 2002a; Nilsson 2004). Severe parkinsonism may be a further risk factor, but the prospective studies are somewhat conflicting; duration of illness does not appear to be a risk factor (Aarsland 2001; Hughes 2000). The development of dementia associated with PD increases caregiver distress, nursing home requirements, mortality twofold, and reduces quality of life (Bedard 2003; Burn 2003).

Diagnostic criteria for PDD are problematic as there is inevitably some contamination with other forms of dementia. There are concerns about differentiating the condition from Alzheimer's disease with motor and psychotic symptoms, Dementia with Lewy bodies (DLB) and subcortical vascular dementia. Additionally, cognitive impairment not amounting to dementia commonly occurs in Parkinson's disease (Erkinjuntti 1997). The pathology and symptomatology of PDD and DLB is similar, making the differential di- 
agnosis particularly problematic (Aarsland 2002a; Nilsson 2004). If the Parkinson's disease has existed at least 12 months before the dementia develops, PDD is considered the most appropriate diagnosis. If, however, dementia occurs within 12 months of the onset of parkinsonian symptoms a diagnosis of DLB should be assigned (McKeith 1996). The rationale for a cut off period of 12 months is recognised to be arbitrary (McKeith 1996).

While the inter-relationships are not well established, deficits of multiple neurotransmitter systems, and cerebral circuits result in the cognitive symptoms of PDD (Leroi 2004). The loss of serotonergic and noradrenergic innervations (nerve supplies) are implicated in the cognitive deficits noted in PDD (Jellinger 1994). Decreases in dopaminergic and especially cholinergic functioning are central in mediating the dementia associated with PD (Burn 2003). The progressive loss of dopaminergic functioning in the substantia nigra seen in Parkinson's disease interferes with frontalsubcortical dopaminergic neurons, contributing to the cognitive impairment (Dubois 1997). The cholinergic deficit due to neuronal loss in the nucleus basalis of Meynert correlates to the extent of cognitive impairment (Nakano 1984). Cortical lesions such as those seen in Alzheimer's disease and DLB also occur in PDD (Jellinger 1999). Recent studies have indicated that cholinergic deficits as measured by choline acetyltransferase activity are more significant in PDD compared to both Alzheimer's disease and PD without dementia (Tiraboschi 2000; Ziabreva 2005).

Treatment options in PDD are limited. Dopaminergic agents have been shown to produce only limited, short-term improvements in cognitive functioning (Kulisevsky 2000). Neuroleptic medication could potentially aggravate any movement disorder via antagonism of D2 receptors (Barber 2001). This worsening of movement disorder in Parkinson's disease also occurs with atypical neuroleptics (Graham 1998). While the NMDA-receptor antagonist memantine may be a treatment option there is only very limited data (Lokk 2004). The observation that PDD is associated with decreases in cortical cholinergic functioning implies that cholinesterase inhibitors might be beneficial (Aarsland 2002a; Perry 1985). A number open studies and small scale placebo studies have suggested that cholinesterase inhibitors may be effective in cognitive impairment associated with PD (Aarsland 2002; Aarsland 2002a; Giladi 2003; Hutchinson 1996; Leroi 2004; Reading 2001; Werber 2001). Concerns about tolerability including possible worsening of Parkinson's disease have been expressed. There is a need to evaluate the effects of this class of medication on cognition, physical function and behavioural symptoms, as well as tolerability.

\section{O B J E C T I V E S}

To assess the efficacy, safety, and tolerability of cholinesterase inhibitors in PDD.

\section{MET HODS}

\section{Criteria for considering studies for this review}

\section{Types of studies}

Randomized, double-blind, placebo-controlled studies assessing the efficacy of cholinesterase inhibitors for people with PDD.

\section{Types of participants}

Patients of any age or sex diagnosed with PDD according to standardized methods such as the DSM-IV criteria (APA 1994).

\section{Types of interventions}

Any studies comparing any of the current cholinesterase inhibitors (donepezil, rivastigmine, galantamine and tacrine) against placebo.

\section{Types of outcome measures}

Outcome measures that evaluated the following:

- Neuropsychiatric features, e.g., any psychiatric or behavioural manifestations

- Cognition

- Global clinical impression

- Activities of daily living

- Quality of life

- Caregiver burden

- Parkinsonian features such as tremor and rigidity

- Acceptability of treatment, as determined by withdrawal from trials

- Safety, as measured by the frequency and severity of adverse events

- Institutionalization

- Health Economics

\section{Search methods for identification of studies}

The trials were identified from a last updated search of the Specialized Register of the Cochrane Dementia and Cognitive Improvement Group on 19 April 2005 using the search term parkinson* The Specialized Register at that time contained records from the following databases:

- CENTRAL: January 2005 (issue 1);

- MEDLINE: 1966 to 2005/02;

- EMBASE: 1980 to 2005/01;

- PsycINFO: 1887 to 2005/01;

- CINAHL: 1982 to 2004/12;

Cholinesterase inhibitors for Parkinson's disease dementia (Review) 
- SIGLE (Grey Literature in Europe): 1980 to 2004/06;

- ISTP (Index to Scientific and Technical Proceedings): to

May 2000;

- INSIDE (BL database of Conference Proceedings and

Journals): to June 2000;

- Aslib Index to Theses (UK and Ireland theses): 1970 to March 2003;

- Dissertation Abstract (USA): 1861 to March 2003;

- ADEAR (Alzheimer's Disease Clinical Trials Database): to 25 March 2005;

- National Research Register: issue 1/2005;

- Current Controlled trials (last searched April 2005) which includes:

Alzheimer Society

GlaxoSmithKline

HongKong Health Services Research Fund

Medical Research Council (MRC)

NHS R\&D Health Technology Assessment Programme

Schering Health Care Ltd

South Australian Network for Research on Ageing

US Dept of Veterans Affairs Cooperative Studies

National Institutes of Health (NIH)

- ClinicalTrials.gov: last searched March 2005;

- LILACS (Latin American and Caribbean Health Science

Literature): last searched April 2003

A comprehensive search of abstracts from major scientific meetings was performed.

Shire Pharmaceuticals/Janssen-Cilag, Pfizer/Eisai and Novartis ( Novartis 2005) were contacted in September 2004 for information regarding additional and ongoing studies.

\section{Data collection and analysis}

\section{Selection of studies:}

Two reviewers (IM, CF) independently selected trials for relevance against defined inclusion criteria from the Cochrane Collaboration Handbook (Clarke 2001). Trials that did not meet the criteria were excluded. Reviewers' selection of trials were compared and the final list of studies was reached by consensus. Disagreements were resolved by discussion and consultation with a third reviewer. Assessment of methodological quality:

Sources of bias were considered on a study-by-study basis and studies were excluded if two reviewers (CF, IM) agreed that bias was significant. In these cases, exclusions were specified.

\section{Data extraction:}

Data was extracted from the published reports. The summary statistics required for each trial and each outcome for continuous data were the mean change from baseline, the standard error of the mean change, and the number of patients for each treatment group at each assessment. Where changes from baseline were not reported, the mean, standard deviation and the number of patients for each treatment group at each time point were extracted, if available.

For binary data the numbers in each treatment group and the numbers experiencing the outcome of interest were sought.

The baseline assessment was defined as the latest available assessment prior to randomization, but no longer than two months prior.

For each outcome measure, data were sought on every patient randomized. To allow an intention-to-treat analysis, the data were sought irrespective of compliance, whether or not the patient was subsequently deemed ineligible or otherwise excluded from treatment or follow-up. If intention-to-treat data were not available in the publications, "on-treatment" or the data of those who complete the trial were sought and indicated as such.

In studies where a cross-over design was used, only data from the first treatment phase after randomization were eligible for inclusion.

Data from titration phases prior to the randomized phase were not used to assess safety or efficacy because patients were usually not randomized, nor were treatments concealed.

Rating scales: A significant number of rating scales are used to assess outcomes within Mental Health. Scales vary in quality and many are poorly validated. Outcomes measured using unpublished rating scales or scales with no established reliability or validity were excluded from the review.

Individual patient data were sought for all included studies when the published data were inadequate.

\section{Data analysis:}

The outcomes measured in clinical trials of dementia and cognitive impairment often arise from ordinal rating scales. Where the rating scales used in the trials had a reasonably large number of ordered categories (more than ten) the data were be treated as continuous outcomes arising from a normal distribution.

Summary statistics (n, mean and standard deviation) were required for each rating scale at each assessment time, for each treatment group in each trial, for change from baseline. For crossover trials only the data from the first treatment period were used.

When change from baseline results was not reported, the required summary statistics were calculated from the baseline and assessment time treatment group means and standard deviations. In this case a zero correlation between the measurements at baseline and assessment time were assumed. This method overestimates the standard deviation of the change from baseline, but this conservative approach is considered to be preferable in a meta-analysis.

The meta-analysis required the combination of data from the trials that may not have used the same rating scale to assess an outcome. The measure of the treatment difference for any outcome was the weighted mean difference when the pooled trials used the same rating scale or test, and the standardised mean difference, which is the absolute mean difference divided by the standard deviation when different rating scales or tests were used. 
The duration of the trials may vary considerably. If the range was considered too great to combine all trials into one meta-analysis, it was divided into smaller time periods and a separate meta-analysis conducted for each period. Some trials contributed data to more than one time period if multiple assessments were done.

For binary outcomes, such as clinical improvement or no clinical improvement, the odds ratio was used to measure treatment effect. A weighted estimate of the typical treatment effect across trials was calculated.

Overall estimates of the treatment difference were presented. In all cases the overall estimate from a fixed effects model was presented and a test for heterogeneity using a standard chi-square statistic or the $\mathrm{I}^{2}$ statistic were performed. If, however, there was evidence of heterogeneity of the treatment effect between trials then either only homogeneous results were pooled, or a random-effects model was used (in which case the confidence intervals were broader than those of a fixed-effects model).

\section{Subgroup analysis:}

Where relevant, and data were available, subgroup analysis included age, sex, type and severity of impairment, duration of treatment and details of individual cholinesterase inhibitors.

\section{RES U L T S}

\section{Description of studies}

See: Characteristics of included studies; Characteristics of excluded studies; Characteristics of ongoing studies.

One 24-week study comparing rivastigmine with placebo met the inclusion criteria (Emre 2004). Five hundred and forty-one patients were randomized in a ratio of 2 to 1 to receive rivastigmine or placebo. Rivastigmine was started at a dose of $1.5 \mathrm{mg}$ twice daily and increased to a maximum of $6 \mathrm{mg}$ twice daily over 16 weeks. Baseline characteristics were similar in both groups. The mean age and percentage female was 72.8 years and $35.4 \%$ with rivastigmine, and 72.4 years and $34.6 \%$ with placebo. No patients with a black or oriental race or ethnic group were included in the study population. Patients had a diagnosis of mild to moderately severe dementia, which had developed at least 2 years after PD was diagnosed. The mean MMSE was 19.4 (rivastigmine) and 19.2 (placebo). Most patients (91.1\%) had one or more co-existing medical condition most commonly a psychiatric disorder (40.3\%) and a vascular disorder (35.5\%). The most common CNS medications were levodopa (95.6\% in rivastigmine group, $94.4 \%$ in placebo group) and dopamine agonists $(45.6 \%$ with rivastigmine and $46.4 \%$ with placebo). Details of non-CNS medications were not given. For full details of the study, see table of included studies. Scales:

The primary outcome measures were:
1. The Alzheimer's Disease Assessment Scale - Cognitive sub-scale (ADAS-Cog) (Rosen 1984). The ADAS-Cog contains 11 different tests, spoken language ability (0 to 5), comprehension of spoken language ( 0 to 5$)$, recall of test instructions ( 0 to 5 ), word finding difficulty (0 to 5 ), following commands ( 0 to 5 ), naming objects (0 to 5$)$, construction drawing ( 0 to 5$)$, ideational praxis (0 to 5$)$, orientation (0 to 8 ), word recall (0 to 10$)$ and word recognition (0 to 12$)$. The total score ranges from 0 to 70 with higher scores indicating greater impairment.

2. The Alzheimer's Disease Cooperative Study - Clinician's Global Impression of Change (ADCS-CGIC) (Schneider 1997) evaluates the global change in functioning from baseline. A score of 1 indicates marked improvement, 2 indicates moderate improvement, 3 indicates minimal improvement, 4 indicates no change, 5 indicates minimal worsening, 6 indicates moderate worsening and 7 indicates marked worsening.

The secondary outcome measures were :

1. The Mini Mental State Examination (MMSE) (Folstein 1975) evaluates cognition in five domains; orientation, immediate recall, attention and calculation, delayed recall and language. The test takes 15 minutes to administer with scores ranging from 0 (severe impairment) to 30 (normal).

2. The Alzheimer's Disease Cooperative Study - Activities of Daily Living (ADCS-ADL) (Galasko 1997) evaluates activities of daily living. Scores range from 0 to 78 with higher scores indicating better functioning.

3. The 10-item Neuropsychiatric Inventory (NPI) (Cummings 1994). The NPI is a relatively brief interview that assesses 10 types of behavourial disturbance; delusions, hallucinations, dysphoria, anxiety, agitation/aggression, euphoria, disinhibition, irritability/ lability, apathy and aberrant motor behaviour. Scores range from 0 (normal) to 120 (severely disturbed).

4. The Cognitive Drug Research (CDR) Computerized Assessment System (Simpson 1991) power of attention tests evaluate simple and complex reaction times and digit vigilance. Scores are measured in milliseconds with higher scores indicating a worse performance.

5. The Delis-Kaplan Executive Function System (D-KEFS) Verbal Fluency test (Delis 2001) requires patients to produce as many words as they can in one minute starting with a particular letter. Higher scores indicate better performance.

6. The Ten Point Clock-Drawing test (Manos 1994). Scores range from 0 to 10 with higher results indicating better performance. 7. The Unified Parkinson's Disease Rating Scale (UPDRS) (Fahn 1987) motor subsection was utilised to assess changes in motor function and parkinsonian symptoms. Scores range from 0 to 108 with higher scores indicating more severe motor symptoms.

\section{Risk of bias in included studies}

The included study (Emre 2004) randomly assigned patients to rivastigmine or placebo in a ratio of 2 to 1 . At each treatment centre 
patients were allocated the lowest available identification number. Automated random treatment allocation was conducted with a validated system managed by Novartis Drug Supply Management. Blocking was carried out according to study centre. Personnel directly involved in the study and patients were blind to allocation. There was a $24.2 \%$ drop-out rate, the main reason being adverse events. The last observation carried forward (LOCF) was utilised if follow-up data were lacking. Observed case results were reported as being 'consistent with results in the primary population' (Emre 2004).

\section{Effects of interventions}

One study comparing rivastigmine with placebo in 541 patient met the inclusion criteria (Emre 2004).

- Alzheimer's Disease Assessment Scale - Cognitive sub-scale (ADAS-Cog)

The ADAS-Cog found that using the LOCF the change score from baseline to week 24 significantly favoured rivastigmine [WMD 2.80, $95 \% \mathrm{Cl}-4.26$ to $-1.34, \mathrm{P}=0.0002]$.

- Alzheimer's Disease Cooperative Study - Clinician's Global Impression of Change (ADCS-CGIC)

The ADCS-CGIC found that using the LOCF the change score from baseline to week 24 significantly favoured rivastigmine [WMD $-0.50,95 \% \mathrm{Cl}-0.77$ to $-0.23, \mathrm{P}=0.0004]$. Clinically meaningful (moderate or marked) improvement was observed in $19.8 \%$ of patients in the rivastigmine group and $14.5 \%$ of those in the placebo group. Clinically meaningful (moderate or marked) worsening was observed in $13.0 \%$ patients in the rivastigmine group and $23.1 \%$ of those in the placebo group.

- The Mini Mental State Examination (MMSE)

The MMSE found that using the LOCF the change score from baseline to week 24 significantly favoured rivastigmine [WMD $1.00,95 \% \mathrm{Cl} 0.33$ to $1.67, \mathrm{P}=0.003$ ].

- Alzheimer's Disease Cooperative Study - Activities of Daily Living (ADCS-ADL)

The ADCS-ADL found that using the LOCF the change score from baseline to week 24 significantly favoured rivastigmine [WMD 2.50, 95\% $\mathrm{Cl} 0.43$ to $4.57, \mathrm{P}=0.02$ ].

- The 10-item Neuropsychiatric Inventory (NPI)

The 10-item test found that using the LOCF the change score from baseline to week 24 significantly favoured rivastigmine [WMD 2.00, $95 \% \mathrm{Cl}-3.91$ to $-0.09, \mathrm{P}=0.04]$.

- Cognitive Drug Research (CDR) Computerized

Assessment System - Power of Attention battery (POA)

The CDR POA battery found that using the LOCF there was no statistically significant group difference in the change score from baseline to week 24 [WMD $-173.70,95 \% \mathrm{Cl}-471.23$ to $123.83, \mathrm{P}=0.25]$. The improvement on $\mathrm{CDR}$ power of attention tests is presented as statistically significant in Emre et al, where it was modeled, but was not statistically significant when the raw difference was entered into RevMan.

- Delis-Kaplan Executive Function System (D-KEFS) Verbal Fluency test

The D-KEFS found that using the LOCF the change score from baseline to week 24 significantly favoured rivastigmine [WMD $2.80,95 \%$ CL 1.47 to $4.13, \mathrm{P}<0.0001]$. This test was not performed at all centres.

- Unified Parkinson's Disease Rating Scale (UPDRS)

Full UPDRS results were not reported, but there was no significant group difference in UPDRS motor scores $(\mathrm{P}=0.83)$ including tremor type events $(\mathrm{P}=0.84)$.

\section{Adverse events:}

Significantly fewer patients on placebo suffered one or more adverse event than on rivastigmine [127/179 versus 303/362, OR $2.10,95 \% \mathrm{Cl} 1.37$ to $3.22, \mathrm{P}=0.0006]$. Compared to rivastigmine significantly fewer patients on placebo experienced nausea [20/ 179 versus $105 / 362$, OR $3.25,95 \% \mathrm{Cl} 1.94$ to $5.45, \mathrm{P}<0.00001$ ], vomiting [3/179 versus $60 / 362$, OR $11.66,95 \% \mathrm{Cl} 3.60$ to 37.72 , $\mathrm{P}<0.0001]$, tremor [7/179 versus 37/362, OR $2.80,95 \% \mathrm{Cl}$ 1.22 to $6.41, \mathrm{P}=0.01]$ or dizziness [ $2 / 179$ versus $21 / 362$, OR $5.45,95 \% \mathrm{Cl} 1.26$ to $23.51, \mathrm{P}=0.02$ ]. This increased incidence of tremor appears to contradict the UPDRS results. One possible explanation is that the UPDRS motor subscale lacks sensitivity to detect an increase in tremor in patients suffering from dementia. Significantly more patients on placebo than on rivastigmine experienced orthostatic hypotension [9/179 versus $6 / 362$, OR 0.32 , $95 \% \mathrm{Cl} 0.11$ to $0.91, \mathrm{P}=0.03]$ and hallucinations [17/179 versus $17 / 362$, OR $0.47,95 \% \mathrm{Cl} 0.23$ to $0.94, \mathrm{P}=0.03$ ].

Although the confidence intervals are wide, patients taking rivastigmine were significantly less likely to die within the 24 weeks of the study than those taking placebo [4/362 versus $7 / 179$, OR $0.27,95 \%$ CI 0.08 to $0.95, \mathrm{P}=0.04]$.

There were no significant group differences in terms of the incidence of diarrhoea, anorexia, falls, hypotension, constipation, confusion and serious adverse events.

At 24 weeks the death rate was significantly higher with placebo [7/179 versus $4 / 362$, OR $0.27,95 \% \mathrm{Cl} 0.08$ to $0.95, \mathrm{P}=0.04]$.

\section{Drop out rates:}

Significantly more patients on rivastigmine dropped out before the end of treatment at 24 weeks due to any reason [99/362 versus $32 / 179$, OR $1.73,95 \% \mathrm{Cl} 1.11$ to $2.70, \mathrm{P}=0.02]$ or due to an adverse event $[62 / 362$ versus $14 / 179$, OR $2.44,95 \% \mathrm{Cl} 1.32$ to 4.48, $\mathrm{P}=0.004]$

\section{DISCUSSION}

When evaluating the evidence base for any treatment three key issues should be considered: the treatment, the study population 
and the outcome. Currently there is only one RCT reported investigating the efficacy of rivastigmine that met our inclusion criteria (Emre 2004). We are, therefore, unable to comment on the use of other cholinesterase inhibitors. The population in the single included study was limited to patients with mild to moderately severe dementia and excluded black or oriental racial groups.

The primary outcome measures and all but one of the secondary measures indicated a statistically significant effect. The 2.80 point improvement on the ADAS-Cog at 24 weeks is comparable to that noted with cholinesterase inhibitors in Alzheimer's disease and is equivalent to a delay of 6 months in the disease pathology. Furthermore, the functional and global measures indicated statistical significance. The results must be treated with caution for three reasons. First, in a degenerative disorder the use of LOCF may enhance the final outcome. This effect may be significant if there is a high drop out rate and when there is differential drop out rate between study arms. Thus the use of LOCF may have biased the results in favour of active therapy. Second, tolerability issues may negatively influence patient acceptability as evidenced by the higher drop out rate in the active arm. Third, statistical significance does not always equate with clinical significance. For example, a 2-point difference on the 10-item NPI (range of scores 0 to 120 ) is unlikely to be clinically significant (Fox 2003; Sink 2005). On the other hand, there was a 5.3\% difference in the rate of detectable changes that had a positive effect on clinical status, and a $10.1 \%$ difference in changes that had a detectable negative effect on clinical status. These differences both favoured rivastigmine over placebo.

Unfortunately, the study did not report the effect of rivastigmine in PDD on institutionalization rates, quality of life measures for both patients and carers and health economic factors.

\section{A U THORS' CONCLUSIONS}

\section{Implications for practice}

There is clear evidence from one RCT that rivastigmine had a moderate effect on cognition and to a lesser extent ADL in patients with PDD. Rivastigmine has a clinically meaningful, beneficial effect in $15 \%$ of cases of PDD. The importance of this clinical effect will depend on the individual patient's context. No information is available on cost-effectiveness. Tolerability issues appear significant and will require careful management.

\section{Implications for research}

Studies are required to confirm clear clinically significant efficacy as well as statistically significant efficacy in illness domains in addition to cognition. Studies should utilise other methods in addition to the last observation carried forward to analyse the data and assess health economic factors. Long term trials with clinically in addition to statistically significant outcome measures should be linked to economic analysis of cost-effectiveness. Data is required for other cholinesterase inhibitors and cognitive enhancers and in patients from black and oriental ethnic groupings.

\section{ACKNOWLEDGEMENTS}

We gratefully acknowledge the contributions of the consumer editor Christine Bridges and Jacqueline Birks from the Cochrane Dementia and Cognitive Improvement Group who provided statistical advice and analysis. We also acknowledge the peer reviewers and contact editor Rupert McShane who greatly assisted in improving the text.

\section{R E F E R E N C E S}

\section{References to studies included in this review}

Emre 2004 \{published data only\}

Emre M, Aarsland D, Albanese A, Byrne EJ, Deuschl G, DeDeyn PP, Durif F, Kulisevsky J, van Laar T, Lees A, Poewe W, Robillard A, Rosa MM, Wolters E, Quarg P, Tekin S, Lane R. Rivastigmine for Dementia Associated with Parkinson's Disease. New England Journal of Medicine 2004;351:2509-18.

Emre M, Onofrj M, Tekin S, Quarg P, Lane R, Express Study Group. Benefits of Rivastigmine in Parkinson's Disease Dementia: Results from the EXPRESS Study. NeuroBiology of Aging 2004;25(S2):19.

Lees AJ. An extension study to investigate the effect of exelon (rivastigmine) on parkinson's disease dementia. National Research Register 2003.

Poewe W//EXPRESS Study Group. Long-Term Benefits of Rivastigmine in Dementia Associated with Parkinson's Disease: An Open-Label Extension Study. 57th Annual Meeting of the American Academy of Neurology, Miami Beach, April 2005. 2005.

\section{References to studies excluded from this review}

Aarsland 2002 \{published data only\}

* Aarsland D. Galantamine for Parkinson's disease with dementia. European Neuropsychopharmacology 2002;12: S378-379.

Aarsland D, Hutchinson M, Larsen JP. Cognitive, psychiatric and motor response to galantamine in Parkinson's disease with dementia. International journal of geriatric psychiatry 2003;18(10):937-41.

Aarsland 2002a \{published data only\}

Aarsland D, Laake K, Larsen JP, Janvin C. Donepezil for cognitive impairment in Parkinson's disease: a randomized 
control trial. Journal of Neurology and Neurosurgery Psychiatry 2002;72:708-12.

Bergman 2002 \{published data only\}

Bergman J, Lerner V. Successful use of donepezil for the treatment of psychotic symptoms in patients with Parkinson's disease.. Clinical neuropharmacology 2002;25 (2):107-10.

Bergman 2003 \{published data only\}

Bergman J, Brettholz I, Shneidman M, Lerner V.

Donepezil as add-on treatment of psychotic symptoms in patients with dementia of the Alzheimer's type.. Clinical neuropharmacology 2003;26(2):88-92.

Fabbrini 2002 \{published data only\}

Fabbrini G, Barbanti P, Aurilia C, Pauletti C, Lenzi GL, Meco G. Donepezil in the treatment of hallucinations and delusions in Parkinson's disease. Neurological Sciences 2002; 23:41-3.

Fogelson 2003 \{published data only\} Fogelson N, Kogan E, Korczyn AD, Giladi N, Shabtai H, Neufeld MY. Effects of rivastigmine on the quantitative eeg in demented parkinsonian patients. Acta Neurologica Scandinavica 2003;107(4):252-5.

Foy 2000 \{published data only\}

Foy C. The non-dopaminergic neuropharmacology of idiopathic Parkinson's Disease. Thesis submitted in fulfilment for a Doctor of Philosophy, Section of Clinical Neurology, University of Sheffield (accessed from the British Library) 2000.

Grunewald RA. Investigation of the effects of rivastigmine on cognition in Parkinson's disease. National Research Register 1999.

Giladi 2003 \{published data only\}

Giladi N, Shabtai H, Gurevich T, Benbunan B, Anca M, Korczyn AD. Rivastigmine for dementia in patients with Parkinson's disease. Acta Neurol Scand 2003;108:368-73.

Hutchinson 1996 \{published data only\}

Hutchinson M, Fazzini E. Cholinesterase inhibition in Parkinson's disease. Journal of Neurology, Neurosurgery \& Psychiatry 1996;61:324-5.

Korczyn 2001 \{published data only\}

Korczyn AD, Shabati H, Benbunan B, Gurevich T, Anca M, Sidis S, Giladi N. The effect of treatment with Rivastigmine (Exelon) on cognitive functions of patients with dementia and Parkinson's disease. Parkinsons Related Disorders 2001; 7:S61.

Leroi 2004 \{published data only\}

Leroi Iracema, Brandt Jason, Reich Stephen G, Lyketsos Constantine G, Grill Stephen, Thompson Richard, Marsh Laura. Randomized placebo-controlled trial of donepezil in cognitive impairment in Parkinson's disease.. International Journal of Geriatric Psychiatry 2004;19(1):1-8.

McKeith 2000a \{published data only\}

McKeith IG. A pilot study into the effects of donepezil on cognitive impairment and neuropsychiatric features in patients with dementia with Lewy bodies and Parkinson's disease. National Research Register 2000a.

Reading 2001 \{published data only\}

Reading PJ, Luce AK, McKeith IG. Rivastigmine in the treatment of Parkinson's psychosis and cognitive impairment: preliminary findings from an open trial. Mov Disorder 2001;16:1171-95.

\section{Van Laar 2001 \{published data only\}}

Van Laar T, de Vries JJ, Nakhosteen A, Leenders KL. Rivastigmine as anti-psychotic treatment in patients with Parkinson's disease. Parkinsons Related Disorders 2001;7: S73.

\section{Werber 2001 \{published data only\}}

Werber EA, Rabey JM. The beneficial effect of cholinesterase inhibitors on patients suffering from parkinson's disease and dementia. Journal of Neural Transmission 2001;108(11): 1319-25.

\section{References to studies awaiting assessment}

\section{Burn 2005 \{published data only\}}

Burn D, Emre M, McKeith I, Hsu C, Lane R. Response to Rivastigmine in Patients with and without Visual Hallucinations in Dementia Associated with Parkinson's Disease (EXPRESS Study Group). 57th Annual Meeting of the American Academy of Neurology, Miami Beach, April 2005. 2005:S25.004.

\section{References to ongoing studies}

Anon 2004a \{published data only\}

Anon. Donepezil to treat dementia in Parkinson's disease. ClinicalTrials.gov 2004.

\section{Marion 2003 \{published data only\}} Marion MH. An open 24 week prospective, randomised, double-blind placebo controlled prallel group study of efficacy, tolerability and safety of 3-12 mg/day of exelon and exelon (rivastigmine) capsules in patients with Parkinson's disease dementia. National Research Register 2003.

\section{Additional references}

\section{Aarsland 2001}

Aarsland D, Andersen K, Larsen JP, Lolk A, Nielsen H, Kragh-Sorensen P. Risk of dementia in Parkinson's disease A community based, prospective study. Neurology 2001;56: $730-6$.

\section{APA 1994}

American Psychiatric Association. Diagnostic and Statistical Manual of Mental Disorders (DSM IV). 4th Edition. Washington DC, USA: American Psychiatric Association, 1994.

\section{Barber 2001}

Barber R, Panikker A, McKeith IG. Dementia with Lewy bodies: diagnosis and management. Int J Geriatr Psychiatry 2001;16:S12-8. 
Bedard 2003

Bedard MA, Agid Y, Chouinard S, et al.Mental and

Behavioural dysfunction in movement disorders. Totowa, NJ: Humana Press, 2003.

\section{Burn 2003}

Burn DJ, McKeith IG. Current treatment of dementia with lewy bodies and dementia associated with parkinson's disease. Movement Disorders 2003;18(SUPPL. 6):S72-S79.

\section{Clarke 2001}

Clarke M, Oxman AD. Cochrane Reviewers Handbook 4.1.2 [updated March 2001]. The Cochrane Library. Oxford: Update Software, 2001, issue 2.

\section{Corey Bloom 2002}

Corey Bloom J. The abc of alzheimer's disease: cognitive changes and their management in alzheimer's disease and related dementias. International Psychogeriatrics 2002;14 (SUPPL. 1):51-75.

\section{Cummings 1988}

Cummings JL. The dementias of Parkinson's disease: Prevalence, characteristics, neurobiology, and comparison with dementia of the Alzheimer type. European Neurology 1988;28(Suppl 1):15-23.

\section{Cummings 1994}

Cummings JL, Mega M, Gray K, Rosenberg-Thompson S, Carusi DA, Gornbein J. The Neuropsychiatric Inventory: comprehensive assessment of psychopathology in dementia. Neurology 1994;44:2308-14.

\section{Delis 2001}

Delis DC, Kaplan B, Kramer JH. Delis-Kaplan executive function system. San Antonio, Texas: Psychological Corporation, 2001.

\section{Dubois 1997}

Dubois B, Pillon B. Cognitive deficits in Parkinson's disease. Journal of Neurology 1997;244:2-8.

Emre 2003

Emre M. Dementia associated with Parkinson's disease. The Lancet Neurology 2003;2(4):229-237.

\section{Erkinjuntti 1997}

Erkinjuntti T, Ostbye T, Steenhuis R, Hatchinski V. The effect of different diagnostic criteria on the prevalence of dementia. New England Journal of Medicine 1997;337: 1667-74.

\section{Fahn 1987}

Fahn S, Elton RL, Members of the UPDRS Development Committee. Unified Parkinson's disease rating scale. In: Fahn S, Marsden CD, Calne DB, Goldstein M editor(s). Recent developments in Parkinson's disease. Florham Park, NJ: Macmillan Healthcare Information, 1987:153-64.

\section{Folstein 1975}

Folstein MF, Folstein SE, McHugh PR. Mini-Mental State: a practical method for grading the cognitive state of patients for the clinician. J Psychiatr Res 1975;12:189-98.
Fox 2003

Fox C, Boustani M, Edwards C. Good practice in appraising trials: international guidelines and approaches. International Journal of Psychogeriatrics 2003;15 (S2):27.

\section{Galasko 1997}

Galasko D, Bennett D, Sano M, et al.An inventory to assess activities of daily living for clinical trials in Alzheimer's disease: the Alzheimer's Disease Cooperative Study. Alzheimer Dis Assoc Disord 1997;11 (suppl 2):S33-S39.

\section{Graham 1998}

Graham JM, Sussman JD, Ford KS, Sagar HJ. Olanzapine in the treatment of hallucinosis in idiopathic parkinson's disease: a cautionary tale. J Neurol Neurosurg Psychiatry 1998;65:774-7.

\section{Granholm 2003}

Granholm E, Morris S, Galasko D, Shults C, Rogers E, Vukov B. Tropicamide effects on pupil size and pupillary light reflexes in Alzheimer's and Parkinson's disease.. International journal of psychophysiology official journal of the International Organization of Psychophysiology 2003;47(2): 95-115.

\section{Hughes 2000}

Hughes TA, Ross HF, Musa S, Bhattacherjee SM, Nathen RN, Mindham RHS, Spokes EGS. A 10-year study of the incidence of and factors dementia in predicting Parkinson's. Neurology 2000;54:1596-1602.

\section{Jellinger 1994}

Jellinger KA, Bancher CH, Fischer P. Neuropathological correlates of mental dysfunction in Parkinson's disease. In: Wolters EC, Scheltens PH editor(s). Mental Dysfunction in Parkinson's Disease. Dordrecht: ICG Printing, 1994: 141-61.

\section{Jellinger 1999}

Jellinger KA. Neuropathological correlates of mental dysfunction in Parkinson's disease: an update. In: Wolters EC, Scheltens PH, Berendse HW editor(s). Mental Dysfunction in Parkinson's Disease. Utrecht: Academic Pharmaceutical Publications BV, 1999:82-105.

\section{Kulisevsky 2000} Kulisevesky J, Garcia-Sanchez C, Berthier ML, Barbanoj M, Pascual-Sedano B, Gironell A, Estevez-Gonzalez A. Chronic effects of dopaminergic replacement on cognitive function in Parkinson's disease: a two-year follow-up study of previously untreated patients. Mov Disord 2000;15: 613-26.

\section{Lokk 2004}

Lokk J. Memantine can relieve certain symptoms in Parkinson disease. Improvement achieved in two out of three described cases with dyskinesia and cognitive failure. Lakartidningen 2004;101:2003-6.

\section{Manos 1994}

Manos PJ, Wu R. The ten point clock test: a quick screen and grading method for cognitive impairment in medical and surgical patients. Int J Psychiatry Med 1994;24:229-44. 


\section{McKeith 1996}

McKeith IG, Galasko D, Kosaka K, Perry EK, Dickson DW, Hansen LA, et al.Consensus guidelines for the clinical and pathologic diagnosis of dementia with Lewy bodies (DLB): report of the consortium on DLB international workshop. Neurology 1996;47:1113-24.

\section{Mori 2002}

Mori S. Responses to donepezil in Alzheimer's disease and Parkinson's disease.. Annals of the New York Academy of Sciences 2002;977:493-500.

\section{Nakano 1984}

Nakano I, Hirano A. Parkinson's disease: neuron loss in the nucleus basalis without concomitant Alzheimer's disease. Annals of Neurology 1984;15:415-8.

\section{Nilsson 2004}

Nilsson FM. Psychiatric and cognitive disorders in Parkinson's disease. Current Opinion in Psychiatry 2004;17: 197-202.

\section{Novartis 2005}

Novartis Pharmaceuticals. Personal communication November 2005. Novartis.

\section{Perry 1985}

Perry EK, Curtis M, Dick DJ, Candy JM, Atack JR, Bloxham CA, et al.Cholinergic correlates of cognitive impairment in Parkinson's disease: comparsions with Alzheimer's disease. J Neurol Neurosurg Psychiatry 1985;48: 413-21.

Pirker 2003

Pirker W, Fischer P. Cholinesterase inhibitors in the treatment of parkinson's disease dementia and dementia with lewy bodies. Journal fur Neurologie, Neurochirurgie und Psychiatrie 2003;4(3):6-10.

Putt 2002

Putt ME, Ravina B. Randomized, placebo-controlled, parallel group versus crossover study designs for the study of dementia in Parkinson's disease.. Controlled clinical trials 2002;23(2):111-26.

Rascol 2002

Rascol O, Goetz C, Koller W, Poewe W, Sampaio C. Treatment interventions for parkinson's disease: an evidence based assessment. Lancet 2002;359(9317):1589-98.

\section{Rosen 1984}

Rosen WG, Mohs RC, Davis KL. A new rating scale for Alzheimer's disease. Am J Psychiatry 1984;141:1356-64.

\section{Schneider 1997}

Schneider LS, Olin JT, Doody RS, et al.Validity and reliability of the Alzheimer's Disease Cooperative StudyClinical Global Impression of Change: the Alzheimer's Disease Cooperative Study. Alzheimer Dis Assoc Disord 1997;11 (suppl 2):S22-S32.

\section{Simpson 1991}

Simpson PM, Surmon DJ, Wesnes KA, Wilcock GK. The cognitive drug research computerized assessment system for demented patients: a validation study. Int $J$ Geriatr Psychiatry 1991;6:95-102.

Sink 2005

Sink KM, Holden KF, Yaffe K. Pharmacological treatment of neuropsychiatric symptoms of dementia: a review of the evidence. JAMA 2005;293:596-608.

\section{Tiraboschi 2000}

Tiraboschi P, Hansen LA, Alford M, Sabbagh MN, Schoos B, Masliah E, Thal LJ, Corey-Bloom J. Cholinergic dysfunction in diseases with Lewy bodies. Neurology 2000; 54:407-411.

Zhang 1993

Zhang ZX, Roman GC. Worldwide occurrence of Parkinson's disease: An updated review. Neuroepidemiology 1993;12:195-208.

\section{Ziabreva 2005}

Ziabreva I, Ballard CG, Aarsland D, Larsen JP, McKeith IG, Perry RH, Perry EK. Lewy body disease: Thalamic cholinergic activity related to dementia and parkinsonism. Neurobiology of Aging 2005;May 21:Epub ahead of print.

\section{References to other published versions of this review}

\section{Maidment 2006}

Maidment I, Fox C, Boustani M. Cholinesterase inhibitors for Parkinson's disease dementia. Cochrane Database of Systematic Reviews 2006, Issue 1. [DOI: 10.1002/ 14651858.CD004747.pub2]

* Indicates the major publication for the study 


\section{CHARACTERISTICS OF STUDIES}

\section{Characteristics of included studies [ordered by study ID]}

Emre 2004

\begin{tabular}{|c|c|c|}
\hline Methods & \multicolumn{2}{|l|}{$\begin{array}{l}\text { Randomised, } \\
\text { multicentre, } \\
\text { double-blind, } \\
\text { placebo-controlled. } \\
\text { Duration: } 24 \text { weeks }\end{array}$} \\
\hline Participants & \multicolumn{2}{|c|}{$\begin{array}{l}\text { Countries: Austria, Belgium, Canada, France, Germany, Italy, Holland, Norway, Portugal, Spain, Turkey, } \\
\text { UK. } \\
\text { No. of centres: not stated. } \\
\text { Diagnosis: PD by UK Parkinson's Disease Society Brain Bank criteria; Dementia by DSM-IV (dementia } \\
\text { due to Parkinson's disease code 294.1) } \\
\text { Inclusions: MMSE } 10 \text { to 24; onset of symptoms of dementia more than } 2 \text { years after diagnosis of PD; } \\
\text { regular caregiver. } \\
\text { Exclusions: primary neurodegenerative disease other than PD or dementia; history major depression; pres- } \\
\text { ence of active uncontrolled seizure disorder; disability or unstable disease unrelated to PD; hypersensitivity } \\
\text { rivastigmine or similar drugs; use cholinesterase inhibitor or anticholinergic drug. } \\
\text { Number of patients: } 541 \text {. }\end{array}$} \\
\hline Interventions & \multicolumn{2}{|c|}{$\begin{array}{l}\text { Route: oral } \\
\text { Treatment: rivastigmine commenced at } 1.5 \mathrm{mg} \text { twice daily and increased according to tolerability by } 3 \mathrm{mg} \\
\text { daily at intervals of at least } 4 \text { weeks over a } 16 \text { week period }\end{array}$} \\
\hline Outcomes & \multicolumn{2}{|c|}{$\begin{array}{l}\text { Primary outcome measures: Alzheimer's Disease Assessment Scale - Cognitive sub-scale (ADAS-Cog); } \\
\text { Alzheimer's Disease Cooperative Study - Clinician's Global Impression of Change (ADCS-CGIC) } \\
\text { Secondary measures: Mini Mental State Examination (MMSE); Alzheimer's Disease Cooperative Study } \\
\text { - Activities of Daily Living (ADCS-ADL); Neuropsychiatric Inventory (NPI); Cognitive Drug Research } \\
\text { (CDR) Computerized Assessment System power of attention tests; Delis-Kaplan Executive Function } \\
\text { System (D-KEFS) Verbal Fluency test; Ten Point Clock-Drawing test; Unified Parkinson's Disease Rating } \\
\text { Scale (UPDRS) }\end{array}$} \\
\hline Notes & \multicolumn{2}{|c|}{ - data was analysed with the LOCF } \\
\hline \multicolumn{3}{|l|}{ Risk of bias } \\
\hline Item & Authors' judgement & Description \\
\hline Allocation concealment? & Yes & \\
\hline
\end{tabular}


Characteristics of excluded studies [ordered by study ID]

\begin{tabular}{|c|c|}
\hline Study & Reason for exclusion \\
\hline Aarsland 2002 & Open label study \\
\hline Aarsland 2002a & $\begin{array}{l}\text { Diagnostic criteria outside specification } \\
\text { (Diagnostic criteria for PDD - DSM-IV PDD or probable PDD) } \\
\text { (Diagnostic criteria for PD - not stated) }\end{array}$ \\
\hline Bergman 2002 & Open label study \\
\hline Bergman 2003 & Open label study; trial of people with Alzheimer's disease, not Parkinson's \\
\hline Fabbrini 2002 & Open label study \\
\hline Fogelson 2003 & Open label study; non standard outcome measures \\
\hline Foy 2000 & Diagnostic criteria outside specification \\
\hline Giladi 2003 & Open label study \\
\hline Hutchinson 1996 & Open label study \\
\hline Korczyn 2001 & Open label study \\
\hline Leroi 2004 & $\begin{array}{l}\text { Diagnostic criteria outside specification } \\
\text { (Diagnostic criteria for PDD - DSM-IV PDD or cognitive impairment secondary to PD) }\end{array}$ \\
\hline McKeith 2000a & Open label exploratory trial; 20 weeks acitve treatment then 6 weeks of withdrawal \\
\hline Reading 2001 & Open label study \\
\hline Van Laar 2001 & Open label study \\
\hline Werber 2001 & Open label study \\
\hline
\end{tabular}

\section{Characteristics of ongoing studies [ordered by study ID]}

\section{Anon 2004a}

Trial name or title

Donepezil for dementia in Parkinson's disease: A randomized double blinded placebo controlled crossover trial

Methods 
Anon 2004a (Continued)

\begin{tabular}{ll}
\hline Participants & $\begin{array}{l}\mathrm{N}=28 \\
\text { Country }=\text { USA } \\
\text { Duration }=26 \text { weeks }\end{array}$ \\
\hline Interventions & Donepezil +// Placebos// \\
\hline Outcomes & $\begin{array}{l}\text {-ADAS/cog } \\
\text {-cognitive function / } \\
\text {-activities of daily living } \\
\text {-mood } \\
\text {-quality of life } \\
\text {-side effects } \\
\text {-motor performance }\end{array}$ \\
\hline Starting date & February 2002 \\
\hline Contact information & Study ID numbers 020115; 02-N-0115//NLM identifier NCT00030979 \\
\hline Notes & This study does definitely not belong to Leroy 2004 \\
\hline
\end{tabular}

\section{Marion 2003}

\begin{tabular}{ll} 
Trial name or title & $\begin{array}{l}\text { An open 24 week prospective, randomised, double-blind placebo controlled prallel group study of efficacy, } \\
\text { tolerability and safety of 3-12mg/day of exelon and exelon (rivastigmine) capsules in patients with Parkinson's } \\
\text { disease dementia }\end{array}$ \\
\hline Methods & $\begin{array}{l}\mathrm{N}=10 \\
\text { Country }=\mathrm{UK} \\
\text { Participants }\end{array}$ \\
\hline Ruration $=24$ weeks \\
\hline Interventions & unclear \\
\hline Outcomes & due to end 31/12/05 $+/ /$ Dosage of Drug $+/ /$ Placebos \\
\hline Starting date & Marie-Helene.Marion@stgeorges.nhs.uk \\
\hline Contact information & \\
\hline Notes
\end{tabular}


DATA AND ANALYSES

Comparison 1. Rivastigmine (3-12mg/day) vs placebo

Outcome or subgroup title

1 ADAS-Cog (change from baseline at 24 weeks) LOCF

2 ADCS-CGIC (change from baseline at 24 weeks) LOCF

3 ADCS-ADL (change from baseline at 24 weeks) LOCF

4 NPI-10 (change from baseline at 24 weeks) LOCF

5 MMSE (change from baseline at 24 weeks) LOCF

6 CDR (change from baseline at 24 weeks) LOCF

7 D-KEFS (change from baseline at 24 weeks) LOCF

8 Withdrawals before end of treatment at 24 weeks

9 Withdrawals due to adverse event before end of treatment at 24 weeks

10 Number of deaths before end of treatment at 24 weeks

11 At least one adverse event before end of treatment at 24 weeks

12 At least one adverse event of nausea before end of treatment at 24 weeks

13 At least one adverse event of vomiting before end of treatment at 24 weeks

14 At least one adverse event of tremor before end of treatment at 24 weeks

15 At least one adverse event of diarrhoea before end of treatment at 24 weeks

16 At least one adverse event of anorexia before end of treatment at 24 weeks

17 At least one adverse event of a fall before end of treatment at 24 weeks

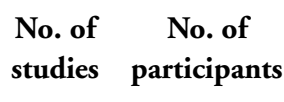

Statistical method

Effect size

$-2.8[-4.26,-1.34]$

$-0.5[-0.77,-0.23]$

$2.5[0.43,4.57]$

$-2.0[-3.91,-0.09]$

$1.0[0.33,1.67]$

$-173.7[-471.23$,

123.83]

2.8 [1.47, 4.13]

$1.73[1.11,2.70]$

2.44 [1.32, 4.48]

$0.27[0.08,0.95]$

2.10 [1.37, 3.22]

$3.25[1.94,5.45]$

$11.66[3.60,37.72]$

$2.80[1.22,6.41]$

$1541 \quad$ Odds Ratio (M-H, Fixed, 95\% CI)

$1.65[0.73,3.73]$

$1541 \quad$ Odds Ratio (M-H, Fixed, $95 \%$ CI)

$2.25[0.84,6.05]$

$1541 \quad$ Odds Ratio (M-H, Fixed, $95 \%$ CI)

$0.94[0.44,2.00]$

541 Odds Ratio (M-H, Fixed, 95\% CI)

Cholinesterase inhibitors for Parkinson's disease dementia (Review)

Copyright $\odot 2010$ The Cochrane Collaboration. Published by John Wiley \& Sons, Ltd. 

treatment at 24 weeks

19 At least one adverse event of hypotension before end of treatment at 24 weeks

20 At least one adverse event of constipation before end of treatment at 24 weeks

21 At least one adverse event of hallucinations before end of treatment at 24 weeks

22 At least one adverse event of confusion before end of treatment at 24 weeks

23 At least one adverse event of

Analysis I.I. Comparison I Rivastigmine (3-I2mg/day) vs placebo, Outcome I ADAS-Cog (change from baseline at 24 weeks) LOCF.

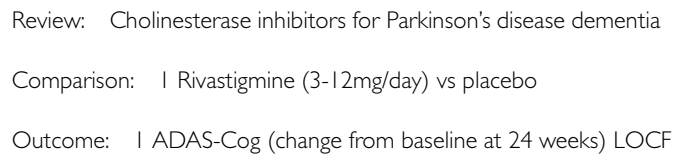

\begin{tabular}{|c|c|c|c|c|c|c|c|}
\hline \multirow[t]{2}{*}{ Study or subgroup } & \multirow{2}{*}{$\begin{array}{r}\text { Rivastigmine } \\
\mathrm{N}\end{array}$} & \multicolumn{3}{|c|}{ Placebo } & \multirow{2}{*}{$\begin{array}{c}\text { Mean } \\
\text { Difference } \\
\text { IV,Fixed,95\% Cl }\end{array}$} & \multirow[t]{2}{*}{ Weight } & \multirow{2}{*}{$\begin{array}{r}\text { Mean } \\
\text { Difference } \\
\text { IV,Fixed,95\% Cl }\end{array}$} \\
\hline & & Mean(SD) & $N$ & Mean(SD) & & & \\
\hline Emre 2004 & 329 & $-2.1(8.2)$ & $|6|$ & $0.7(7.5)$ & & $100.0 \%$ & $-2.80[-4.26,-1.34]$ \\
\hline Total $(95 \%$ CI $)$ & 329 & & 161 & & & $100.0 \%$ & $-2.80[-4.26,-1.34]$ \\
\hline
\end{tabular}

Heterogeneity: not applicable

Test for overall effect: $Z=3.76(P=0.00017)$

Test for subgroup differences: Not applicable 
Analysis I.2. Comparison I Rivastigmine (3-I2mg/day) vs placebo, Outcome 2 ADCS-CGIC (change from baseline at 24 weeks) LOCF.

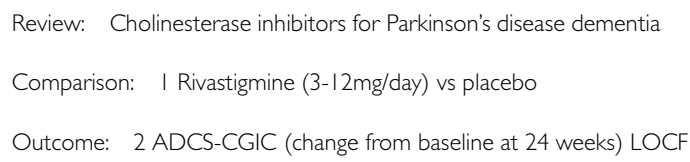

\begin{tabular}{|c|c|c|c|c|c|c|c|}
\hline \multirow[t]{2}{*}{ Study or subgroup } & \multirow{2}{*}{$\begin{array}{r}\text { Rivastigmine } \\
N\end{array}$} & \multicolumn{3}{|c|}{ Placebo } & \multirow{2}{*}{$\begin{array}{c}\text { Mean } \\
\text { Difference } \\
\text { IV,Fixed,95\% Cl }\end{array}$} & \multirow[t]{2}{*}{ Weight } & \multirow{2}{*}{$\begin{array}{r}\text { Mean } \\
\text { Difference } \\
\text { IV,Fixed, } 95 \% \mathrm{Cl}\end{array}$} \\
\hline & & Mean(SD) & N & Mean(SD) & & & \\
\hline Emre 2004 & 329 & $3.8(1.4)$ & 165 & $4.3(1.5)$ & - & $100.0 \%$ & $-0.50[-0.77,-0.23]$ \\
\hline Total (95\% CI) & 329 & & 165 & & & $100.0 \%$ & $-0.50[-0.77,-0.23]$ \\
\hline \multicolumn{8}{|c|}{ Heterogeneity: not applicable } \\
\hline \multicolumn{8}{|c|}{ Test for overall effect: $Z=3.57(P=0.00035)$} \\
\hline \multicolumn{8}{|c|}{ Test for subgroup differences: Not applicable } \\
\hline
\end{tabular}

Analysis I.3. Comparison I Rivastigmine (3-I $2 \mathrm{mg} /$ day) vs placebo, Outcome 3 ADCS-ADL (change from baseline at 24 weeks) LOCF.

Review: Cholinesterase inhibitors for Parkinson's disease dementia

Comparison: I Rivastigmine (3-12mg/day) vs placebo

Outcome: 3 ADCS-ADL (change from baseline at 24 weeks) LOCF

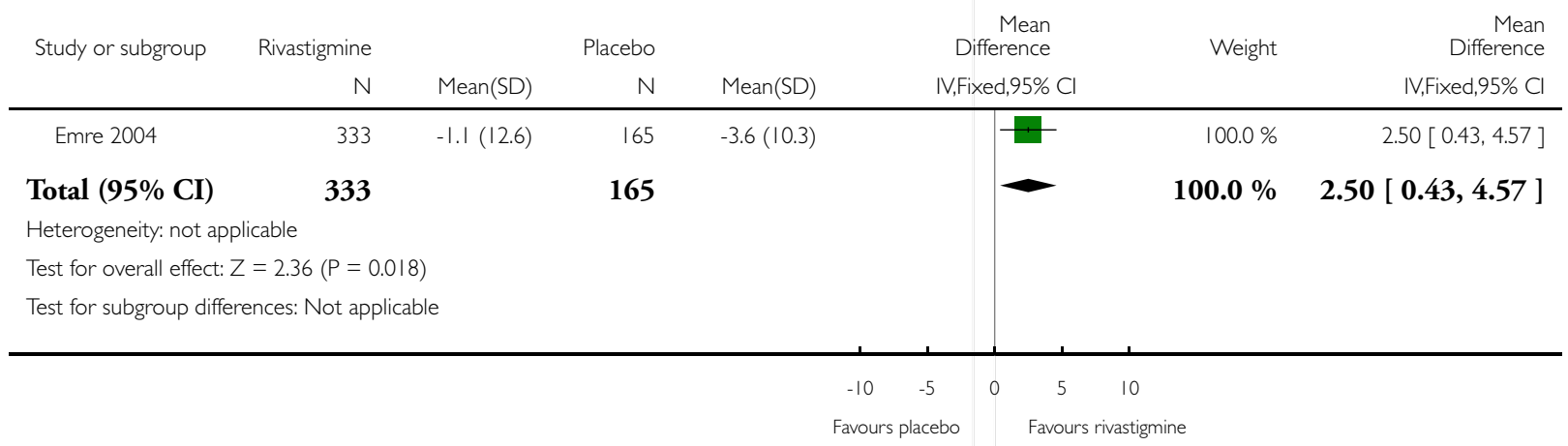


Analysis 1.4. Comparison I Rivastigmine (3-I2mg/day) vs placebo, Outcome 4 NPI- I0 (change from baseline at 24 weeks) LOCF.

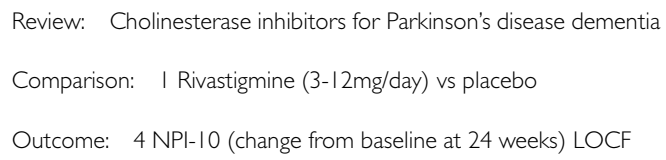

\begin{tabular}{|c|c|c|c|c|c|c|c|}
\hline \multirow[t]{2}{*}{ Study or subgroup } & \multirow{2}{*}{$\begin{array}{r}\text { Rivastigmine } \\
N\end{array}$} & \multicolumn{3}{|c|}{ Placebo } & \multirow{2}{*}{$\begin{array}{c}\text { Mean } \\
\text { Difference } \\
\text { IV,Fixed,95\% Cl }\end{array}$} & \multirow[t]{2}{*}{ Weight } & \multirow{2}{*}{$\begin{array}{r}\text { Mean } \\
\text { Difference } \\
\text { IV,Fixed,95\% C }\end{array}$} \\
\hline & & Mean(SD) & N & Mean(SD) & & & \\
\hline Emre 2004 & 334 & $-2(10)$ & 166 & $0(10.4)$ & & $100.0 \%$ & $-2.00[-3.91,-0.09]$ \\
\hline Total (95\% CI) & 334 & & 166 & & & $100.0 \%$ & $-2.00[-3.91,-0.09]$ \\
\hline \multicolumn{8}{|c|}{ Heterogeneity: not applicable } \\
\hline \multicolumn{8}{|c|}{ Test for overall effect: $Z=2.05(P=0.040)$} \\
\hline \multicolumn{8}{|c|}{ Test for subgroup differences: Not applicable } \\
\hline
\end{tabular}

\section{Analysis I.5. Comparison I Rivastigmine (3-I $2 \mathrm{mg} /$ day) vs placebo, Outcome 5 MMSE (change from baseline} at 24 weeks) LOCF.

Review: Cholinesterase inhibitors for Parkinson's disease dementia

Comparison: I Rivastigmine (3-12mg/day) vs placebo

Outcome: 5 MMSE (change from baseline at 24 weeks) LOCF

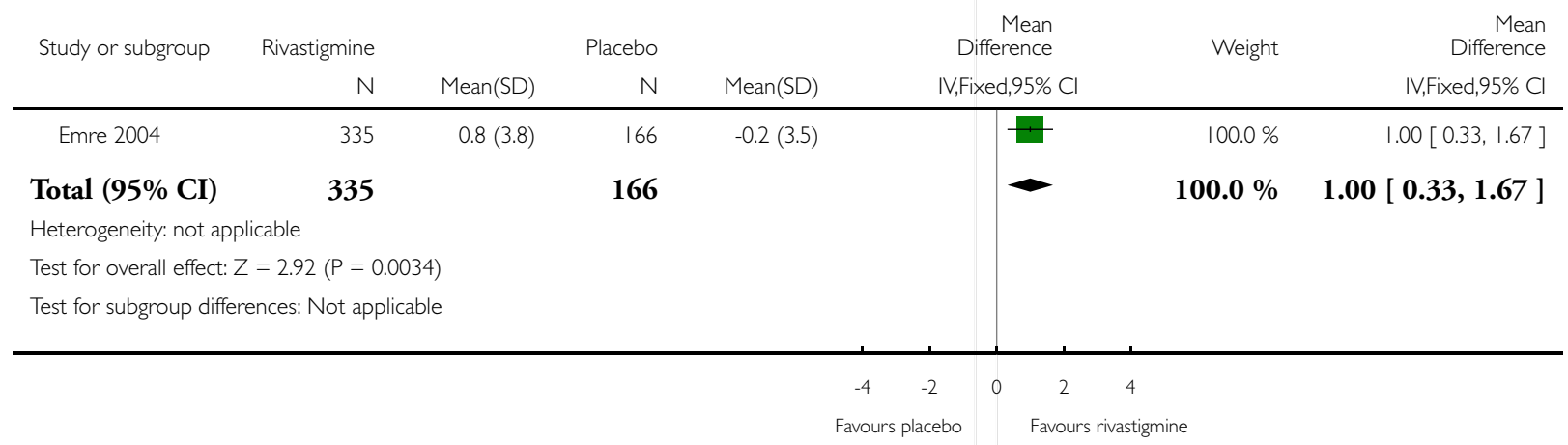




\section{Analysis I.6. Comparison I Rivastigmine (3-12mg/day) vs placebo, Outcome 6 CDR (change from baseline at 24 weeks) LOCF.}

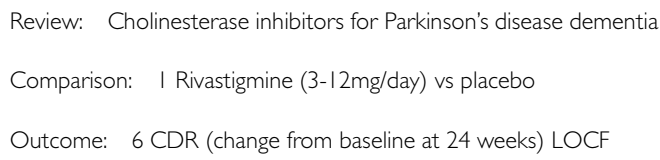

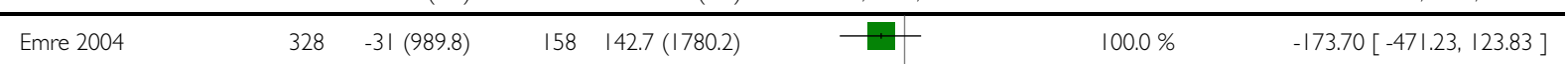

Total $(95 \%$ CI $) \quad 328 \quad 158 \quad-\quad 100.0 \%-173.70[-471.23,123.83]$

Heterogeneity: not applicable

\section{Analysis I.7. Comparison I Rivastigmine (3- I $2 \mathrm{mg} /$ day) vs placebo, Outcome 7 D-KEFS (change from} baseline at 24 weeks) LOCF.

Review: Cholinesterase inhibitors for Parkinson's disease dementia

Comparison: I Rivastigmine (3-12mg/day) vs placebo

Outcome: 7 D-KEFS (change from baseline at 24 weeks) LOCF

\begin{tabular}{|c|c|c|c|c|c|c|c|c|c|}
\hline \multirow[t]{2}{*}{ Study or subgroup } & \multirow{2}{*}{$\begin{array}{r}\text { Rivastigmine } \\
N\end{array}$} & \multicolumn{3}{|c|}{ Placebo } & \multicolumn{3}{|c|}{$\begin{array}{r}\text { Mean } \\
\text { Difference }\end{array}$} & \multirow[t]{2}{*}{ Weight } & \multirow{2}{*}{$\begin{array}{r}\text { Mean } \\
\text { Difference } \\
\text { IV,Fixed,95\% Cl }\end{array}$} \\
\hline & & Mean(SD) & $\mathrm{N}$ & Mean(SD) & & & $\mathrm{ked}, 95 \% \mathrm{Cl}$ & & \\
\hline Emre 2004 & 258 & $1.7(6.8)$ & 144 & $-1.1(6.4)$ & & & +1 & $100.0 \%$ & $2.80[1.47,4.13]$ \\
\hline Total (95\% CI) & 258 & & 144 & & & & $<$ & $100.0 \%$ & $2.80[1.47,4.13]$ \\
\hline \multicolumn{10}{|c|}{ Heterogeneity: not applicable } \\
\hline \multicolumn{10}{|c|}{ Test for overall effect: $Z=4.1$ I ( $P=0.000039)$} \\
\hline \multicolumn{10}{|c|}{ Test for subgroup differences: Not applicable } \\
\hline & & & & & -10 & -5 & 0 & 10 & \\
\hline & & & & & Favour & laceb & Favou & /astigmine & \\
\hline
\end{tabular}


Analysis I.8. Comparison I Rivastigmine (3-I 2mg/day) vs placebo, Outcome 8 Withdrawals before end of treatment at 24 weeks.

Review: Cholinesterase inhibitors for Parkinson's disease dementia

Comparison: I Rivastigmine (3-12mg/day) vs placebo

Outcome: 8 Withdrawals before end of treatment at 24 weeks

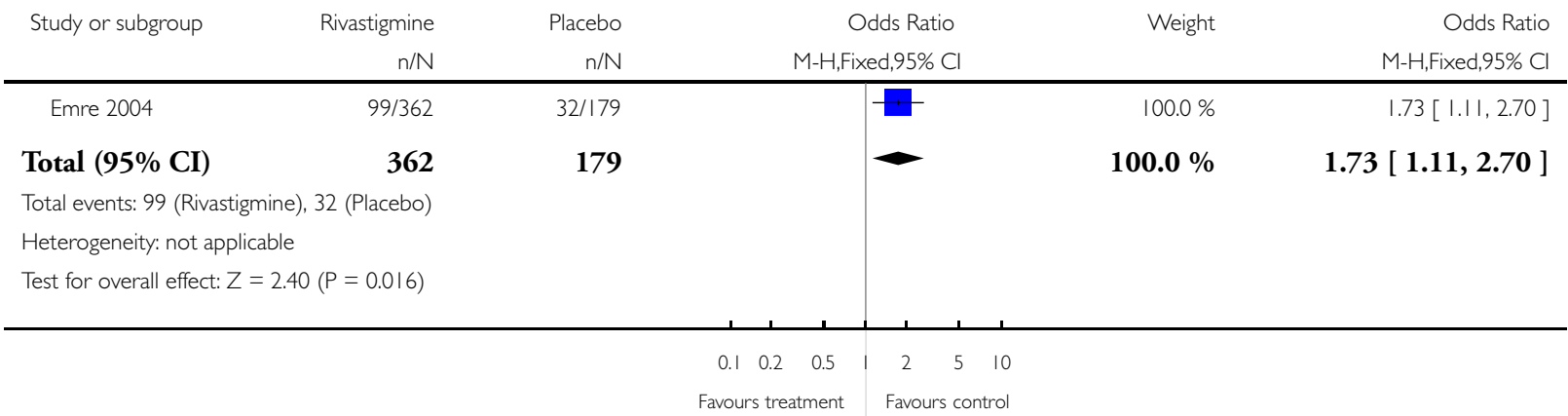

Analysis I.9. Comparison I Rivastigmine (3-I2mg/day) vs placebo, Outcome 9 Withdrawals due to adverse event before end of treatment at 24 weeks.

Review: Cholinesterase inhibitors for Parkinson's disease dementia

Comparison: I Rivastigmine (3-12mg/day) vs placebo

Outcome: 9 Withdrawals due to adverse event before end of treatment at 24 weeks

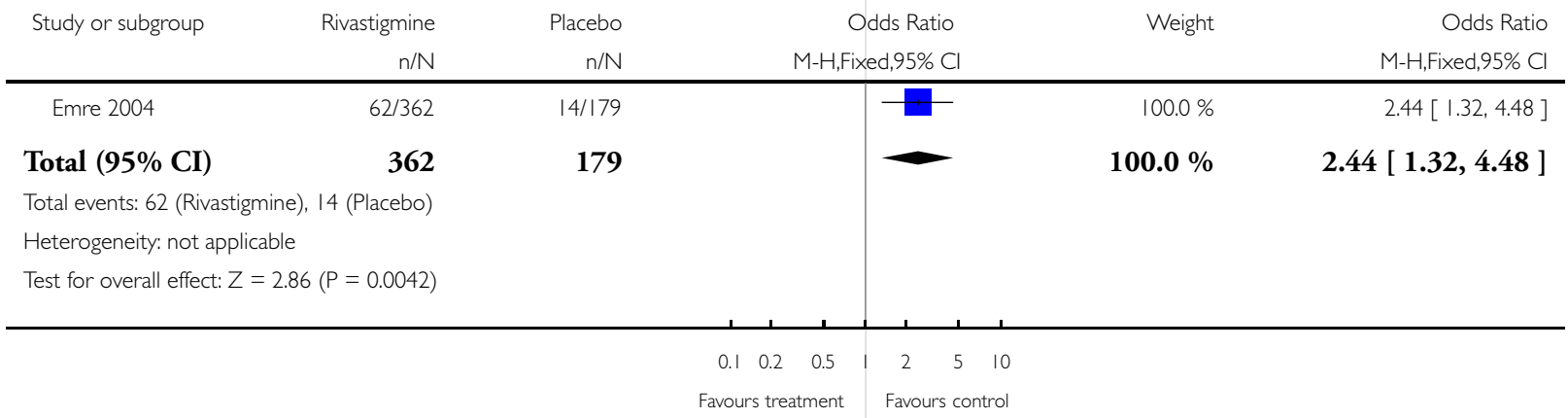


Analysis I.10. Comparison I Rivastigmine (3-12mg/day) vs placebo, Outcome 10 Number of deaths before end of treatment at 24 weeks.

Review: Cholinesterase inhibitors for Parkinson's disease dementia

Comparison: I Rivastigmine (3- I2mg/day) vs placebo

Outcome: 10 Number of deaths before end of treatment at 24 weeks

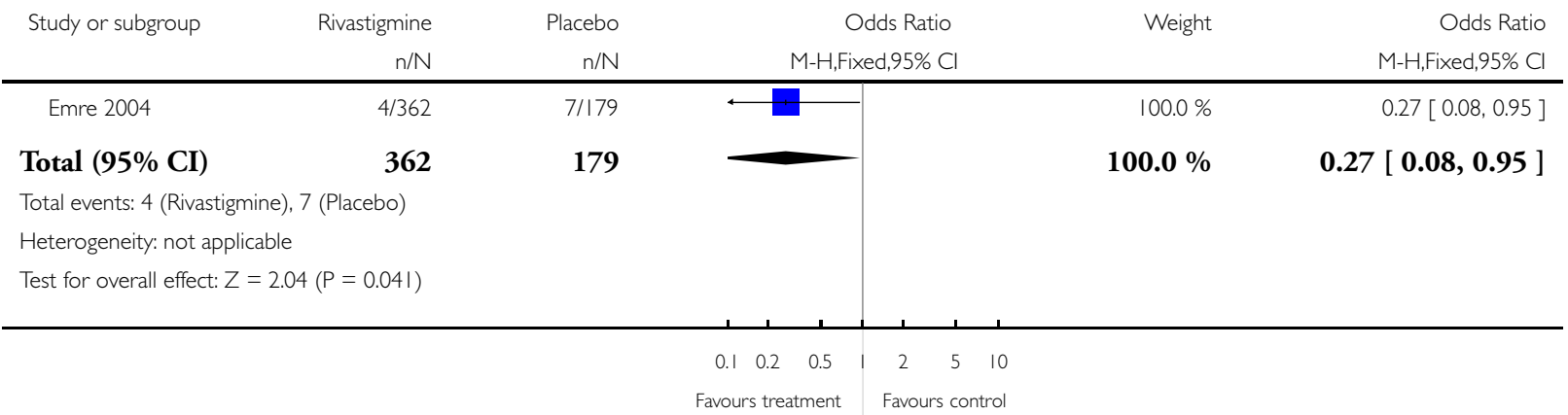

Analysis I.I I. Comparison I Rivastigmine (3- I 2mg/day) vs placebo, Outcome I I At least one adverse event before end of treatment at 24 weeks.

Review: Cholinesterase inhibitors for Parkinson's disease dementia

Comparison: | Rivastigmine (3-12mg/day) vs placebo

Outcome: II At least one adverse event before end of treatment at 24 weeks

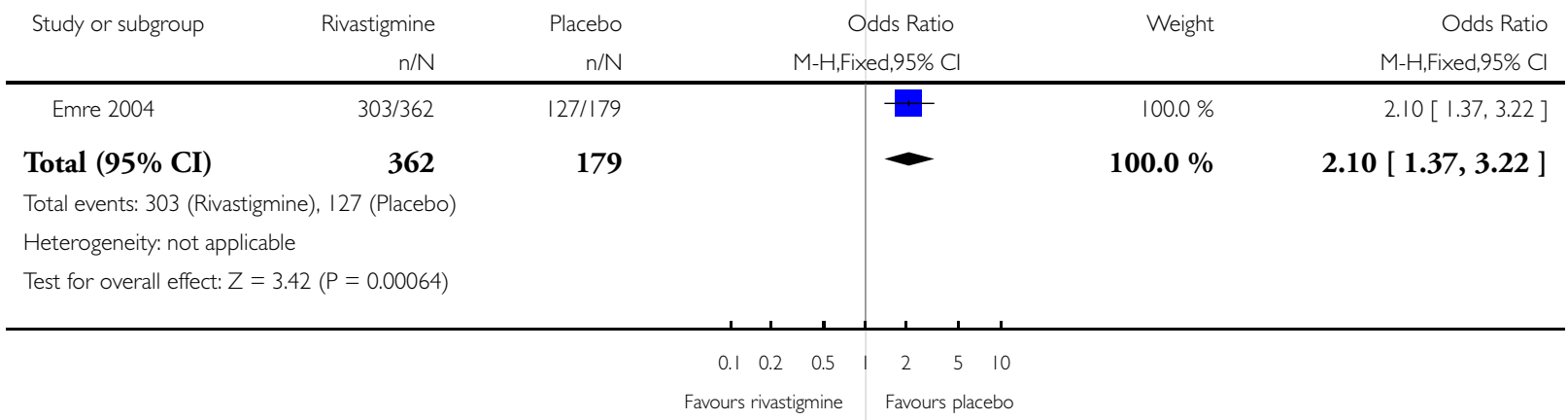


Analysis I.12. Comparison I Rivastigmine (3-I $2 \mathrm{mg} /$ day) vs placebo, Outcome I2 At least one adverse event of nausea before end of treatment at 24 weeks.

Review: Cholinesterase inhibitors for Parkinson's disease dementia

Comparison: I Rivastigmine (3- I2mg/day) vs placebo

Outcome: 12 At least one adverse event of nausea before end of treatment at 24 weeks

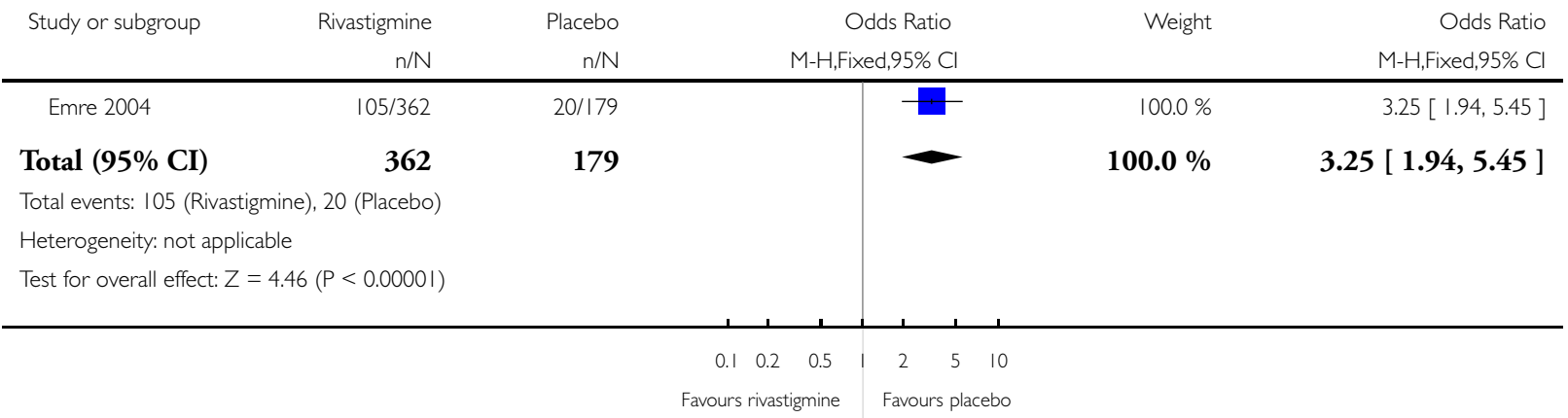

Analysis I.I3. Comparison I Rivastigmine (3-I $2 \mathrm{mg} /$ day) vs placebo, Outcome I3 At least one adverse event of vomiting before end of treatment at 24 weeks.

Review: Cholinesterase inhibitors for Parkinson's disease dementia

Comparison: I Rivastigmine (3-12mg/day) vs placebo

Outcome: 13 At least one adverse event of vomiting before end of treatment at 24 weeks

\begin{tabular}{|c|c|c|c|c|c|}
\hline \multirow[t]{2}{*}{ Study or subgroup } & Rivastigmine & Placebo & Odds Ratio & Weight & Odds Ratio \\
\hline & $\mathrm{n} / \mathrm{N}$ & $\mathrm{n} / \mathrm{N}$ & M-H,Fixed,95\% Cl & & M-H,Fixed,95\% Cl \\
\hline Emre 2004 & $60 / 362$ & $3 / 179$ & . & $100.0 \%$ & $11.66[3.60,37.72]$ \\
\hline Total (95\% CI) & 362 & 179 & & $100.0 \%$ & $11.66[3.60,37.72]$ \\
\hline
\end{tabular}

Total events: 60 (Rivastigmine), 3 (Placebo)

Heterogeneity: not applicable

Test for overall effect: $Z=4.10(P=0.000042)$

$0.01 \quad 0.1$

$10 \quad 100$

Favours rivastigmine Favours placebo 
Analysis I.14. Comparison I Rivastigmine (3-I2mg/day) vs placebo, Outcome I4 At least one adverse event of tremor before end of treatment at 24 weeks.

Review: Cholinesterase inhibitors for Parkinson's disease dementia

Comparison: I Rivastigmine (3- I2mg/day) vs placebo

Outcome: 14 At least one adverse event of tremor before end of treatment at 24 weeks

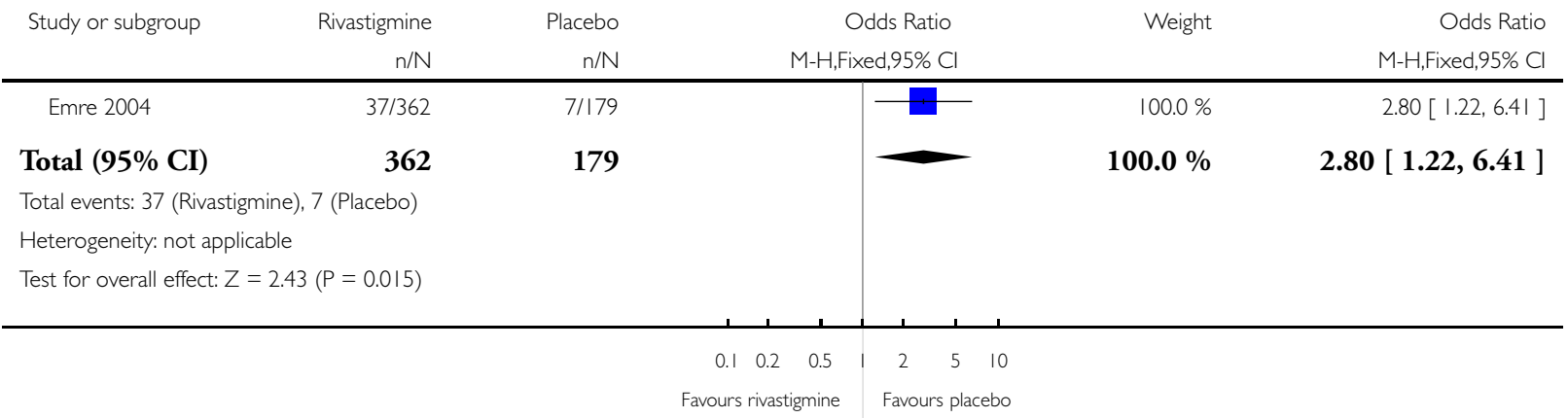

Analysis I.I5. Comparison I Rivastigmine (3-I2mg/day) vs placebo, Outcome I5 At least one adverse event of diarrhoea before end of treatment at 24 weeks.

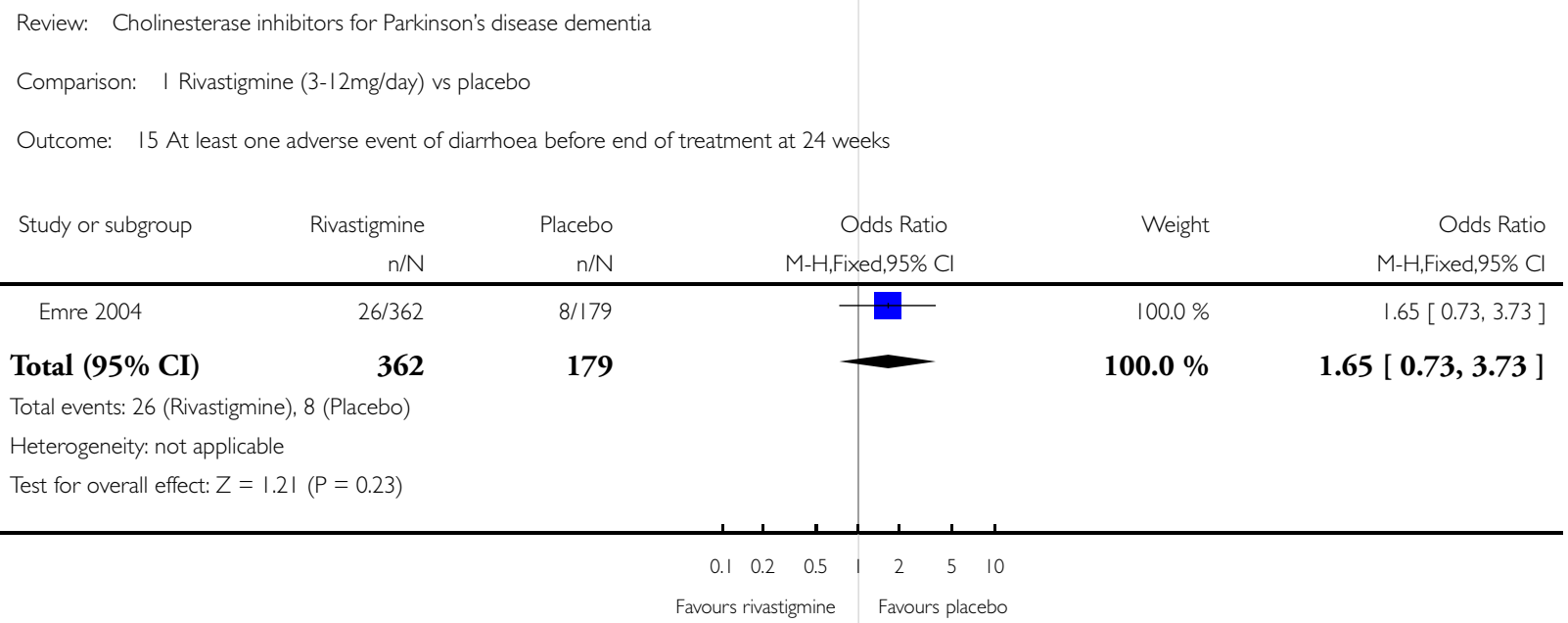


Analysis I.16. Comparison I Rivastigmine (3-12mg/day) vs placebo, Outcome I6 At least one adverse event of anorexia before end of treatment at 24 weeks.

Review: Cholinesterase inhibitors for Parkinson's disease dementia

Comparison: I Rivastigmine (3-12mg/day) vs placebo

Outcome: 16 At least one adverse event of anorexia before end of treatment at 24 weeks

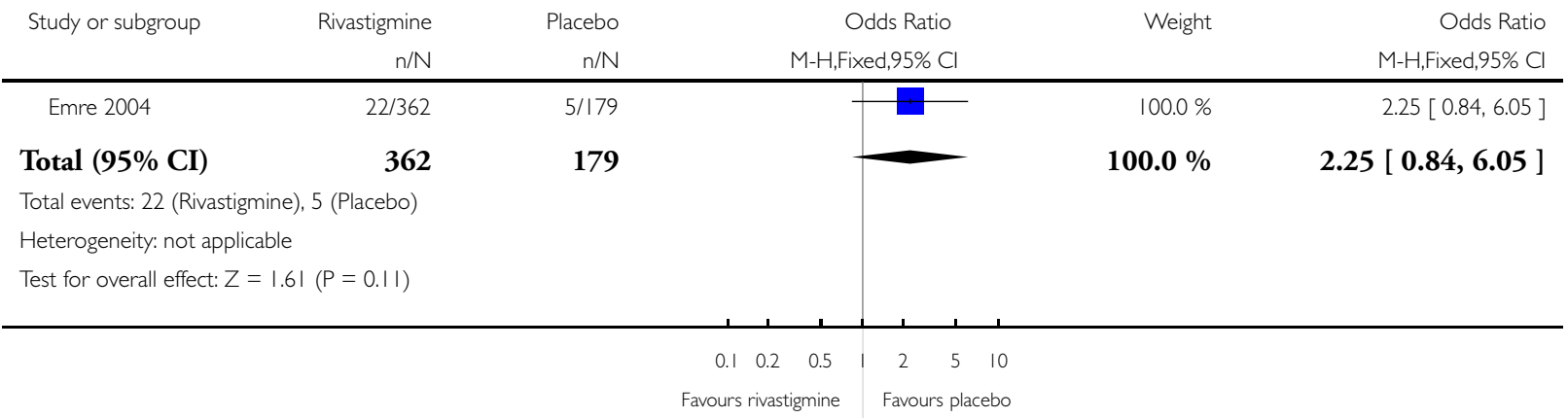

Analysis I.I7. Comparison I Rivastigmine (3-I $2 \mathrm{mg} /$ day) vs placebo, Outcome 17 At least one adverse event of a fall before end of treatment at 24 weeks.

Review: Cholinesterase inhibitors for Parkinson's disease dementia

Comparison: I Rivastigmine (3-12mg/day) vs placebo

Outcome: 17 At least one adverse event of a fall before end of treatment at 24 weeks

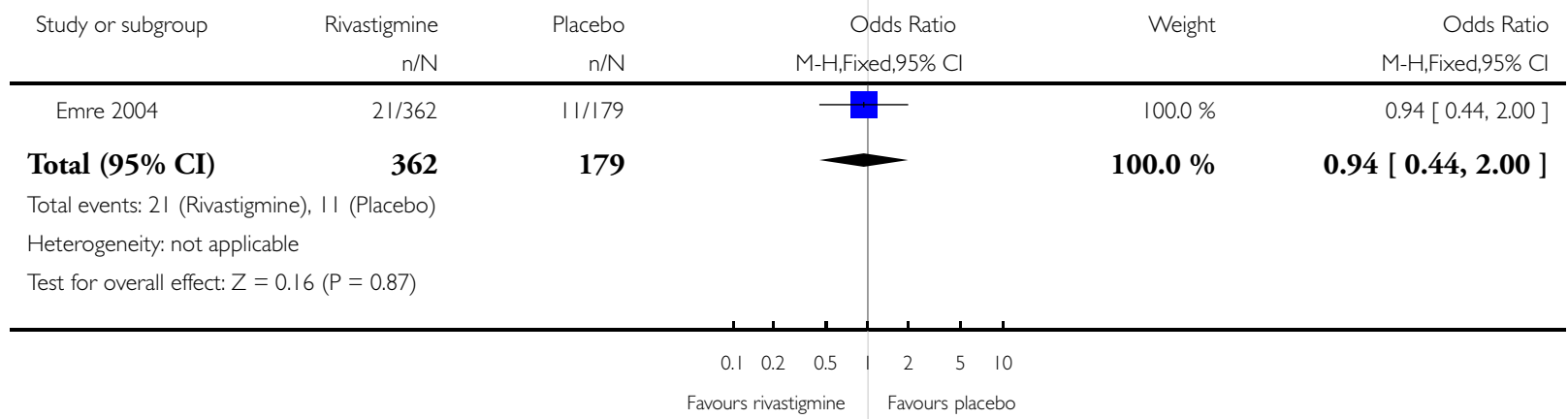


Analysis I.18. Comparison I Rivastigmine (3-I $2 \mathrm{mg} /$ day) vs placebo, Outcome 18 At least one adverse event of dizziness before end of treatment at 24 weeks.

Review: Cholinesterase inhibitors for Parkinson's disease dementia

Comparison: I Rivastigmine (3-12mg/day) vs placebo

Outcome: 18 At least one adverse event of dizziness before end of treatment at 24 weeks

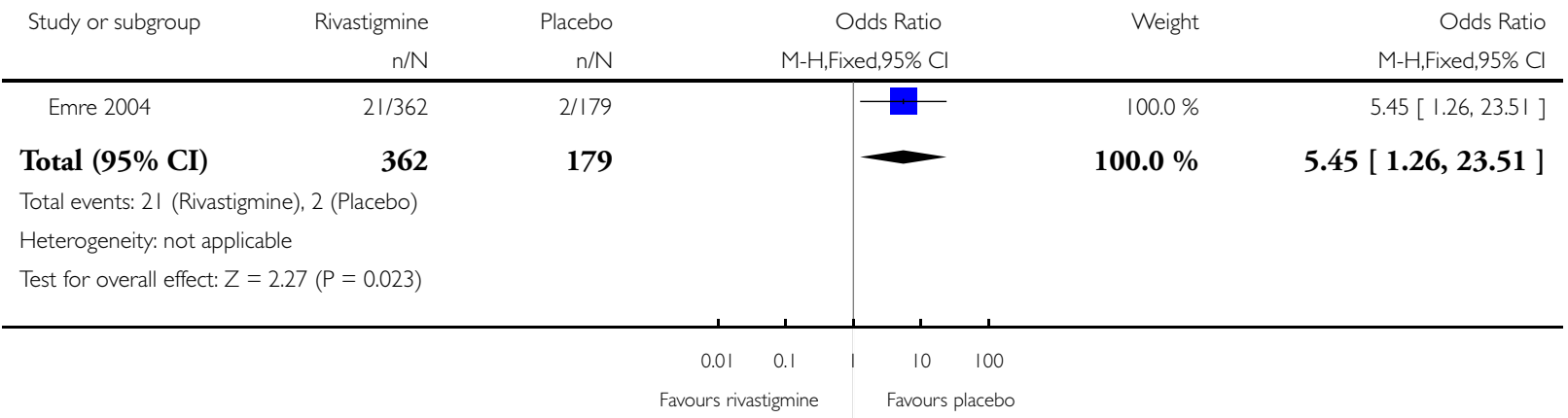

Analysis I.19. Comparison I Rivastigmine (3-12mg/day) vs placebo, Outcome 19 At least one adverse event of hypotension before end of treatment at 24 weeks.

Review: Cholinesterase inhibitors for Parkinson's disease dementia

Comparison: I Rivastigmine (3-12mg/day) vs placebo

Outcome: 19 At least one adverse event of hypotension before end of treatment at 24 weeks

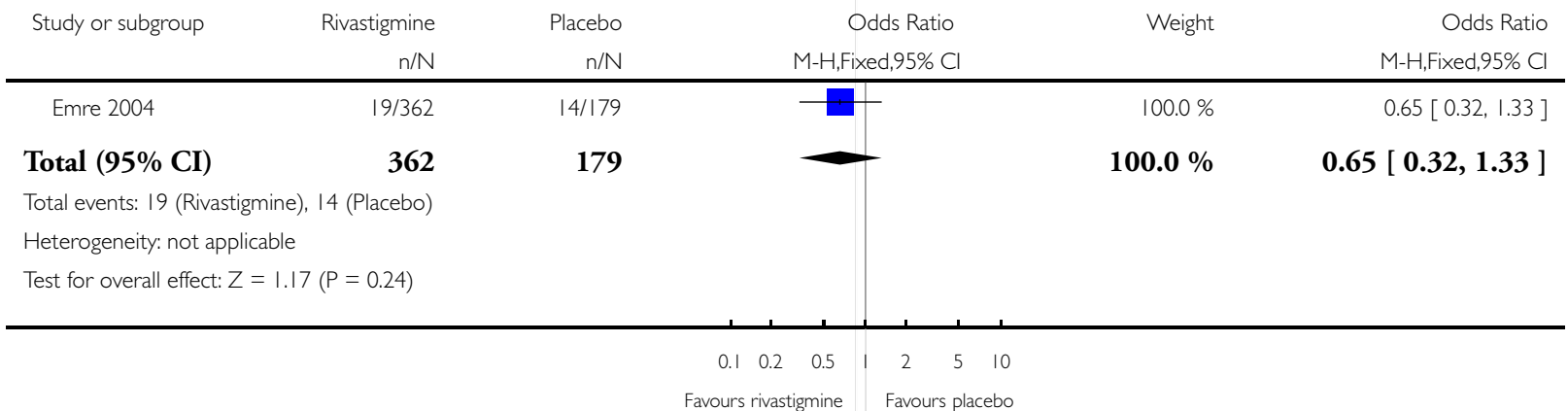


Analysis I.20. Comparison I Rivastigmine (3-I $2 \mathrm{mg} /$ day) vs placebo, Outcome 20 At least one adverse event of constipation before end of treatment at 24 weeks.

Review: Cholinesterase inhibitors for Parkinson's disease dementia

Comparison: I Rivastigmine (3-12mg/day) vs placebo

Outcome: 20 At least one adverse event of constipation before end of treatment at 24 weeks

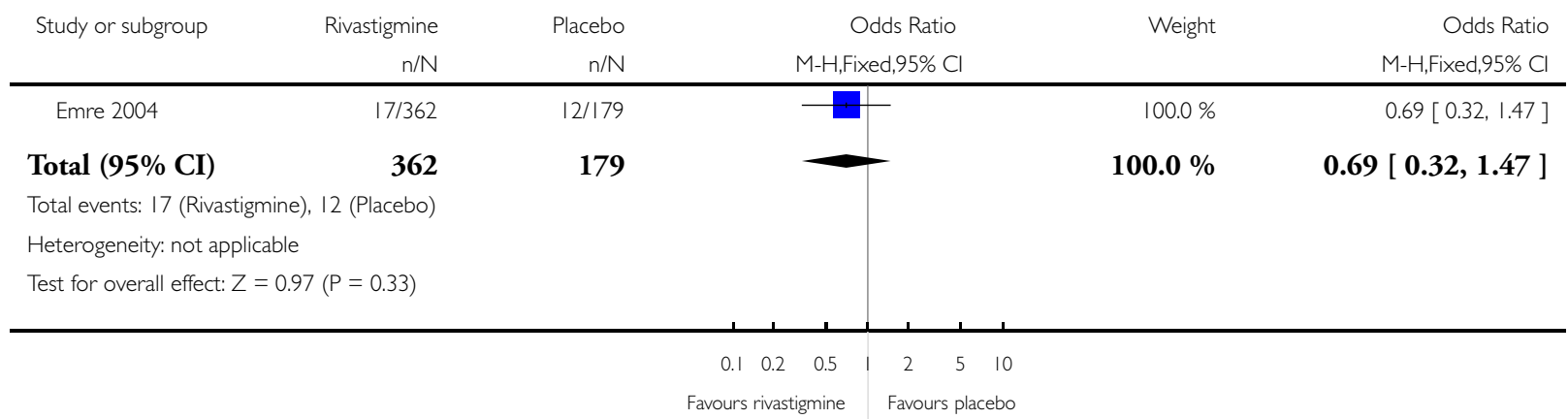

Analysis I.2I. Comparison I Rivastigmine (3-I $2 \mathrm{mg} /$ day) vs placebo, Outcome 2 I At least one adverse event of hallucinations before end of treatment at 24 weeks.

Review: Cholinesterase inhibitors for Parkinson's disease dementia

Comparison: I Rivastigmine (3-12mg/day) vs placebo

Outcome: 21 At least one adverse event of hallucinations before end of treatment at 24 weeks

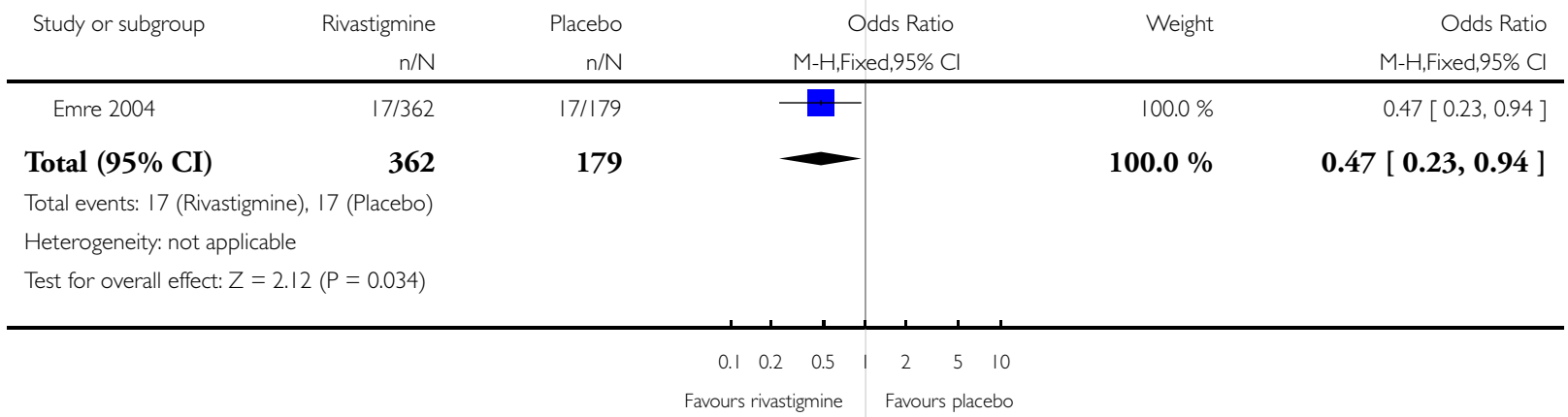


Analysis I.22. Comparison I Rivastigmine (3-I $2 \mathrm{mg} /$ day) vs placebo, Outcome 22 At least one adverse event of confusion before end of treatment at 24 weeks.

Review: Cholinesterase inhibitors for Parkinson's disease dementia

Comparison: I Rivastigmine (3-12mg/day) vs placebo

Outcome: 22 At least one adverse event of confusion before end of treatment at 24 weeks

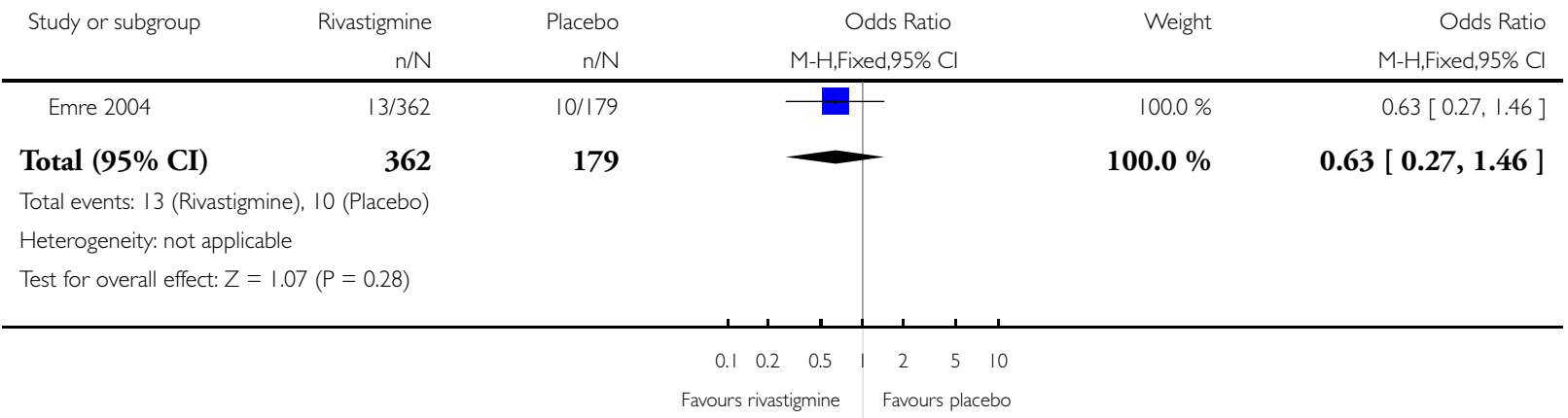

Analysis I.23. Comparison I Rivastigmine (3-I $2 \mathrm{mg} /$ day) vs placebo, Outcome 23 At least one adverse event of orthostatic hypotension before end of treatment at 24 weeks.

Review: Cholinesterase inhibitors for Parkinson's disease dementia

Comparison: I Rivastigmine (3-12mg/day) vs placebo

Outcome: 23 At least one adverse event of orthostatic hypotension before end of treatment at 24 weeks

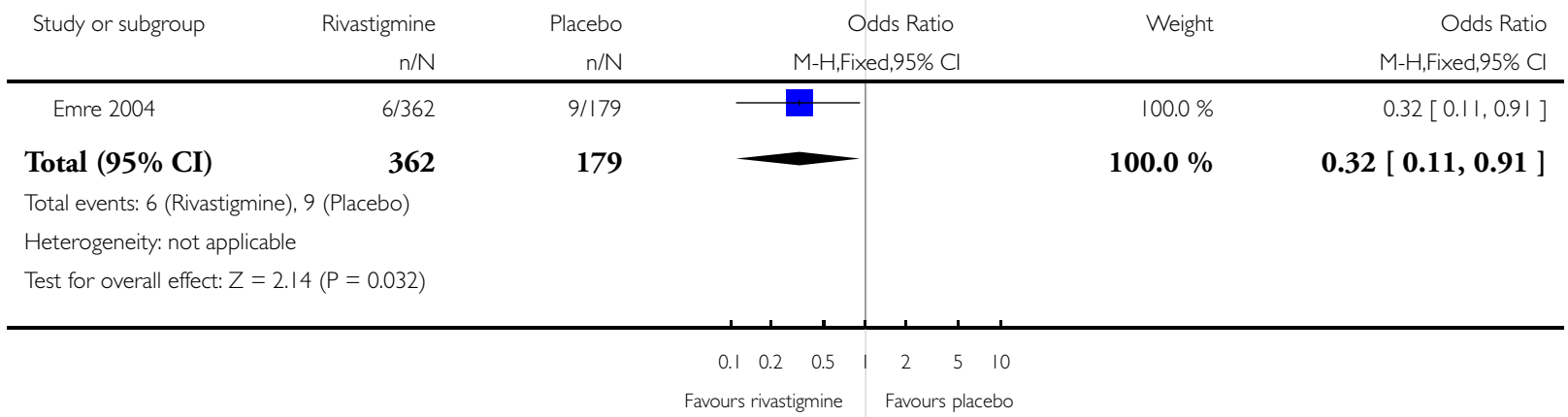




\section{WHAT'S NEW}

Last assessed as up-to-date: 5 May 2008.

\begin{tabular}{|c|c|c|}
\hline Date & Event & Description \\
\hline 6 May 2008 & Review declared as stable & $\begin{array}{l}\text { This review will be withdrawn as it will be subsumed by the review on Cholinesterase } \\
\text { inhibitors for dementia with Lewy bodies, Parkinson's disease dementia and cognitive } \\
\text { impairment in Parkinson's disease, currently in preparation }\end{array}$ \\
\hline
\end{tabular}

\section{H I S T O R Y}

Protocol first published: Issue 2, 2004

Review first published: Issue 1, 2006

\begin{tabular}{|c|c|c|}
\hline Date & Event & Description \\
\hline
\end{tabular}

15 November 2005 New citation required and conclusions have changed Substantive amendment

\section{CONTRIBUTIONSOFAUTHORS}

-IM: main correspondence, search for trials, to select trials for inclusion or exclusion, to extract and enter data. His secondary role is to draft review versions, to obtain copies of trial reports and to interpret the data analysis.

-CF: drafting review versions, obtaining copies of trial reports and interpreting data analysis. His secondary role is to search for trials, select trials for inclusion or exclusion and extract data.

-MB: drafting review versions, selecting trials for inclusion or exclusion, and interpreting results.

Contact editor: Rupert McShane

Consumer editor: Christine Bridges

This review has been peer reviewed in October 2005.

\section{DECLARATIONSOF INTEREST}

Ian Maidment has received honoraria and hospitality from Eisai/Pfizer, Eli Lilly, Novartis, Bristol Myers Squibb, Shire Pharmaceuticals, and Astra Zeneca. He holds no shares in the pharmaceutical industry. Chris Fox has received honoraria and hospitality from Eisai/ Pfizer, Eli Lilly, Novartis, Bristol Myers Squibb, Shire Pharmaceuticals, Lundbeck, J-C and Astra Zeneca. He holds no shares in the pharmaceutical industry. Malaz Boustani has received honoraria and hospitality from Pfizer and Lundbeck. He holds no shares in the pharmaceutical industry.

Cholinesterase inhibitors for Parkinson's disease dementia (Review)

Copyright () 2010 The Cochrane Collaboration. Published by John Wiley \& Sons, Ltd. 


\section{SOURCES OF SUPPORT}

\section{Internal sources}

- East Kent NHS \& Social Care Partnership Trust, UK.

- Kent Institute for Medical Health Studies, UK.

- Regenstrief Institute, USA.

\section{External sources}

- Parkinson's Disease Society, UK.

\section{NDEX TERMS}

\section{Medical Subject Headings (MeSH)}

Cholinesterase Inhibitors [adverse effects; *therapeutic use]; Dementia [*drug therapy; etiology]; Parkinson Disease [ ${ }^{*}$ complications]; Phenylcarbamates [adverse effects; *therapeutic use]; Randomized Controlled Trials as Topic

\section{MeSH check words}

Humans 